This item was submitted to Loughborough's Research Repository by the author.

Items in Figshare are protected by copyright, with all rights reserved, unless otherwise indicated.

\title{
Roadmap layers and processes: resilient and sustainable care facilities
}

PLEASE CITE THE PUBLISHED VERSION

https://doi.org/10.1108/ECAM-06-2016-0136

PUBLISHER

(c) Emerald

VERSION

AM (Accepted Manuscript)

\section{PUBLISHER STATEMENT}

This work is made available according to the conditions of the Creative Commons Attribution-NonCommercialNoDerivatives 4.0 International (CC BY-NC-ND 4.0) licence. Full details of this licence are available at: https://creativecommons.org/licenses/by-nc-nd/4.0/

\section{LICENCE}

CC BY-NC-ND 4.0

\section{REPOSITORY RECORD}

Pantzartzis, Efthimia, Andrew Price, and Francis Tekyi Edum-Fotwe. 2019. "Roadmap Layers and Processes: Resilient and Sustainable Care Facilities". figshare. https://hdl.handle.net/2134/37170. 


\section{Engineering, Construction} and Architectural Management

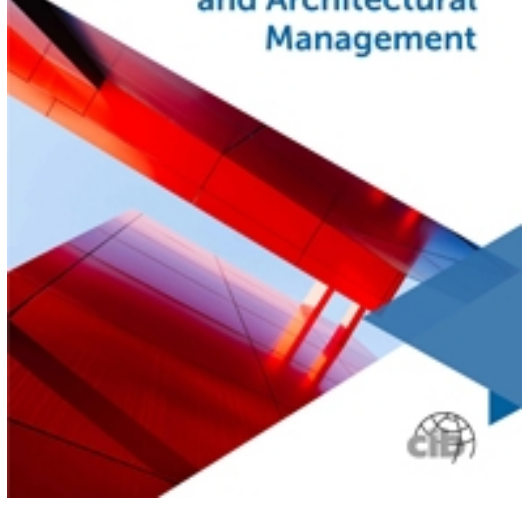

\section{Roadmap layers and processes: resilient and sustainable care facilities}

\begin{tabular}{|r|l|}
\hline Journal: & Engineering, Construction and Architectural Management \\
\hline Manuscript ID & ECAM-06-2016-0136.R2 \\
\hline Manuscript Type: & Original Article \\
\hline Keywords: & Roadmap, Health care, Social care, Resilience, Sustainability, Process \\
\hline Abstract: & \\
\hline \multicolumn{2}{|c}{} \\
\end{tabular}

\section{SCHOLARONE \\ Manuscripts}




\title{
Roadmap layers and processes: resilient and sustainable care facilities
}

\begin{abstract}
Purpose - Health and social care facilities are usually complex buildings that require continuous effort to provide resilient and sustainable responses to changes in demographics, technologies, diseases and models of care. Despite resilience and sustainability concepts being frequently used by practitioners and researchers, ambiguities in their definitions often result in a lack of operational solutions to record, monitor and improve the resilience and sustainability of health and social care facilities. Although the importance and complexity of the issues are widely acknowledged, there is little strategic guidance as to how they should be achieved. The aim of this paper is to: assess the suitability of developing a roadmap for improving the resilience and sustainability of UK health and social care facilities; and identify the layers and processes needed to construct such a roadmap.
\end{abstract}

Design/methodology/approach - A qualitative approach was adopted, starting with a literature review of different types of roadmaps and their suitability to support the desired improvement objectives. Layers and processes were thus developed using the key issues identified in three recent research streams, and the roadmap was structured.

Findings - The major findings have been captured within a three-layer, four-step process generic roadmap for improving the resilience and sustainability of health and social care facilities that can be used to monitor performance, plans future actions and implement response to change.

Practical implications - This paper targets decision-makers, especially estate managers, but the proposed layers and processes can be modified for other stakeholders.

Originality/value - This paper suggests an original approach for the development of a roadmap for resilience and sustainability of health and social care facilities, and specifically of how to structure layers and processes, envisioning a more integrated development of service provision and infrastructure asset management.

Keywords - Roadmap, facilities, performance, health care, social care, resilience, sustainability

Paper type - Research paper 


\section{Introduction}

Health and social care facilities ${ }^{1}$ include some of the most complex building types and many need to be operational 24 hours a day, seven days a week and 52 weeks a year, as do other types of infrastructure (e.g. transport, oil and gas, and justice). Daily access and operability are subject to surges, which can become critical at peak times and/or in when responding to natural and man-made disasters. Changes in demographics, technologies, diseases and models of care represent further sources of performance risk to built health and social care assets, in particular their resilience and sustainability. Current geopolitical, societal and technological challenges being faced by health and social care facilities worldwide were identified by the World Economic Forum (2015). Strategies for health and social care service provision and infrastructure asset management are not always developed together. Also, the life cycles of technology and care models tend to be considerably shorter than those of built assets, thus resulting in poor economic, geopolitical, societal and technological fit.

UK health and social care facilities have increasingly come under scrutiny due to perceived poor quality of service and health outcomes (Francis, 2013; Keogh, 2013). Mills et al. (2015) and Curtis and Burn (2015) suggested that the poor condition of many care facilities combined with new care service demands threatens the resilience and sustainability of existing health and social care facilities. The recent financial crisis and increasing costs of health and social care service provision are further stressing care facilities which are central to national strategies for resilient and sustainable infrastructures, for example "to sustain a comprehensive high-quality NHS [...] on all three fronts - demand, efficiency and funding" (NHS, 2014).

This paper builds off three recent research streams which deal with complementary aspects of care facility resilience and sustainability: 1) backlog maintenance of acute NHS trusts; 2) dementia-friendly design of health and social care environments in England; and 3) English NHS acute hospitals' operational productivity and performance.

Obsolete built assets, an ageing population and rapid change in care models can impact care facility performance, especially when they are not sufficiently resilient to respond to change. The concepts of resilience and sustainability were introduced respectively in the 40s and in the 60 s and have been used interchangeably since then, leaving the debate open to interpretation as well as misinterpretation. Ambiguities in the definitions of resilience and sustainability remain as demonstrate by a lack of universally agreed metrics and tools for assessing care facility performance.

This paper investigates the development and use of roadmaps capable of responding to the current needs of the care facilities in the UK and that can be adapted to future changes. It targets decision-makers involved in the design, construction or operation of health and social care buildings and identifies the layers and processes of a roadmap for resilient and sustainable performance of UK health and social care facilities.

\footnotetext{
${ }^{1}$ Health and care facilities is abbreviated "care facilities" to improve sentence readability where appropriate.
} 
The aim of is paper is to assess the potential of developing a roadmap for improving the resilience and sustainability of UK health and social care facilities. The objectives are to: 1) establish the opportunity of using a roadmap to guide the improvement of resilience and sustainability of health and social care facilities; 2) identify the key factors that are relevant to the resilience and sustainability of care facilities; and 3) develop a generic roadmap structure along with the required layers and processes.

\section{Health and social care facilities in the UK: the challenge}

The National Health Service (NHS) provides health care for patients from 236 Trusts (ERIC, 2017), of which 154 are Acute Trusts with circa 16,000 buildings spread across England. Social care is provided from around 21,407 care homes in England, that may own multiple buildings across different settings as well. The built environment where care is provided represents one of the most interesting challenges of the 21 st century for the Department of Health (DH) England: many old built assets are functionally unsuitable and require robust asset management strategies (Mills et al., 2015). A strategic agenda to develop resilient and sustainable UK critical infrastructure (including public health services) was advocated almost a decade ago (Bosher et al., 2007). The actions envisaged were to protect care infrastructure from extreme natural and human-induced hazards, thus leaving unchallenged a vast array of other threats which are matter of current debate.

The concept of resilience has been largely discussed from a natural and human-induced vulnerability to disasters and emergencies perspective (Manyena, 2006; Bosher et al., 2007; Nirupama et al., 2015; Rogers, 2015), and even more so after the Hyogo Framework for Action (HFA) 2005-2015 (UNISDR, 2005). Yet, it is only the Sendai Framework (SF) for Disaster Risk Reduction that focuses on "promoting resilience of new and existing critical infrastructure, including [...] hospitals and other health facilities, to ensure they remain safe, effective and operational during and after disasters", in the recognition that "effective disaster risk management contributes to sustainable development" (UNISDR, 2015). The SF advocates "building better from the start to withstand hazards through proper design and construction, including the use of the principles of universal design and the standardization of building materials; retrofitting and rebuilding; nurturing a culture of maintenance; and taking into account economic, social, structural, technological and environmental impact assessments".

Sustainability concepts have more frequently been associated with environmental threats originating from the human exploitation of natural resources: the (United Nations, 2015a; United Nations, 2015b) advocated: "resource efficiency; mitigation and adaptation to climate change; resilience to disasters; and development and implementation of holistic risk management". Resilience and sustainability interact and overlap in different ways, and the up-to-date circumstances do not appear to clarify the individual aspects of the two concepts. The UK Government (2005) with "Securing the future" announced a long-term agenda to deliver a sustainable development strategy, including advice on possibilities for sustainable refurbishment of health and social care buildings, built upon: engagement with communities; protection of resources; efficient use of resources; prioritisation of climate change and 
energy; and enabling local communities. However, the agenda did not result in applicable metrics and tools, leaving the stakeholders free to engage or not with the proposed strategy. In 2016 the NHS local councils came together in "Sustainability and Transformation Partnerships (STPs)" to improve NHS services and population health, with the result that each STP developed different STP estate plans depending on their levels of maturity. In January 2019 the "NHS Long Term Plan" was published setting out key ambitions to be achieved over the next 10 years, including a stronger collaboration between health and social care services via "Integrated Care Systems (ICSs) (NHS, 2019). Yet, the ambitious plan calls upon STPs, ICSs and multiple stakeholders to implement the strategies and operationally deliver the targets.

Achour and Price (2010) suggested a "fusion" of resilience and sustainability strategies into a more comprehensive strategy of adaptation to large-scale natural disasters of UK healthcare facilities. Nevertheless, additional driving factors need to be investigated, as the concepts of resilience and sustainability need to be addressed from multiple perspectives besides the economic and the environmental. More recently, Zhong et al. (2014) suggested a wider conceptual framework that seemed to open towards integration within community, thus driving the discussion to fitness-for-purpose of existing built assets.

\section{Research methodology}

This study adopted a qualitative approach that "locates the observer in the world" and "studies things in their natural settings, attempting to make sense of or interpret phenomena in terms of the meanings people bring to them" (Denzin and Lincoln, 2011). The research investigated the processes that are relevant to resilience and sustainability: the nature and the complexity of the processes respond to "how" and "why" (Gabriel and David, 2005); and different research streams (i.e. case studies) enable to explore areas where research is scarce. Building theory from fieldwork leads to a deep understanding of the complex interaction of people, processes, and technology within organisations (Cepeda Carrión et al., 2004). Qualitative research can lead to data overload, which are not always captured by linear path roadmaps (Eisenhardt, 1989), hence raising the need for a cyclical path framework (i.e. planning, data collection, data analysis and critical analysis) (Gabriel and David, 2005).

Haddad and Uriona Maldonado (2017) recently proposed a "functions approach", where seven "functions" (i.e. entrepreneurial activities, knowledge development, knowledge diffusion through networks, guidance of the search, market formation, and resource mobilisation, and creation of legitimacy) can be identified as key drivers, hence enablers, and streams to develop and improve technology roadmaps. Multiple research streams, which build off different case studies, provide "different perspectives to entities", thus building theory and enhancing research credibility (Benbasat et al., 1987). To capture multidimensional aspects, Kim et al. (2009b) merged 30 research programmes, grouped under 12 different "themes", to develop a future-proof technology roadmap for construction Research and Design. Vishnevskiy et al. (2015) proposed an integrated roadmap structure based on multiple "paths" based on the key trends envisioned for each subject field, thus offering the opportunity to evaluate the impact of different factors. 
This paper considers and combines multiple resilience and sustainability factors and develops an 'improvement' roadmap by combining: a) the results of a systematic literature review of technology roadmaps (from now on referred to as roadmaps); and b) the key findings from three recent research streams.

a) The systematic review identified the scope for using roadmaps in the health and social care sector and outlined a conceptual structure. This was conducted as follows.

- A scoping search of the terms "roadmap" and "infrastructure" conducted using multiple databases, including Science Direct, PubMed, and Scopus.

- Two search criteria were adopted: publications within the past 10 years (i.e. 20052016); and publications in which the search terms were in title and abstract.

b) The three research streams aimed at exploring the interaction of multiple driving factors in organisations, facilities and processes. They are discussed as follows.

- Content analysis was conducted for each research stream, to capture key issues within each stream.

- Three stages were considered for each research stream: identify the current needs, capabilities and targets against a shared vision for future change; implement subsequent targets when changes arise; and plan and measure the performance.

\section{Roadmap working definition from literature review}

Almost 20 years ago, Garcia and Bray (1997) described a roadmap as "a document that identifies the critical system requirements, the product and process performance targets and the technology alternatives and milestones for meeting those targets". Further definitions followed, adding dimensions and specifications until more recent days. Strauss et al. (1998) added the strategic dimension, which appears to be fundamental in the current knowledge. Roadmaps are generally defined as strategic and collaborative tools to enable future cooperation among stakeholders in pursuing shared objectives (Albright, 2002; Rinne, 2004; Wells et al., 2004; Lee and Park, 2005; Kamtsiou et al., 2006).

Table 1 summarises the key definitions that have emerged from the literature search.

Table 1. Roadmap definitions from literature

\begin{tabular}{|c|c|}
\hline Author (year) & Definition \\
\hline $\begin{array}{l}\text { Garcia and Bray } \\
\text { (1997) }\end{array}$ & A document generated by the technology road mapping process. \\
\hline Groenveld (1997) & $\begin{array}{l}\text { A strategic decision process framework that: supports enterprise innovation } \\
\text { activities; and contributes to the integration of business and technology. }\end{array}$ \\
\hline $\begin{array}{l}\text { Strauss et al. } \\
(1998)\end{array}$ & $\begin{array}{l}\text { An operational toolset based on strategic plan requirements for selecting which } \\
\text { technologies/products to pursue and in what timeframes. }\end{array}$ \\
\hline $\begin{array}{l}\text { Brown and O'Hare } \\
(2001)\end{array}$ & $\begin{array}{l}\text { A visual aid which crystallises the links between research programmes, } \\
\text { development programmes, capability targets and requirements. }\end{array}$ \\
\hline Kappel (2001) & $\begin{array}{l}\text { A strategic document to: establish market, product and technology priorities; } \\
\text { extend them using forecasts to set targets; and links them through R\&D } \\
\text { investments. }\end{array}$ \\
\hline Albright (2002) & $\begin{array}{l}\text { A planning tool to help the team communicate their objectives and plans (i.e. } \\
\text { discipline to ensure there are no gaps in the plan) to the larger development } \\
\text { team, to other corporate functions. }\end{array}$ \\
\hline
\end{tabular}


Probert and

Radnor (2003)

Phaal et al. (2004)

Petrick and Echols

(2004)

Rinne (2004)

Wells et al. (2004)

Lee and Park (2005) (2006)

Gerdsri and Kocaoglu (2007)

Froese and Rankin (2009)

Ardalan et al. (2012)

Crowley and Lipschutz (2013)

Klinckenberg et al. (2013)

Lee et al. (2013)
Kamtsiou et al.

The view of a group of stakeholders as to how to get where they want to go to achieve their desired objective.

An approach to support the development, communication and implementation of technology and business strategy.

A tool to enable managers making sustainable new product development decisions.

A tool for managing the future of technologies and the products that implement them.

A communication/knowledge management tool supporting strategic decisionmaking.

A method for supporting the strategic management of technology (i.e. planning, forecasting, and administration).

A tool for collaborative strategic planning that enables us to make strategies and take actions towards the desired future, with special emphasis on anticipating changes in technologies and new business opportunities.

A collective approach to developing a strategy in which the integration of science/ technological considerations represents a valuable input into product and business planning.

A framework based on three classification facets (i.e. application area, technology, and innovation lifecycle phase) defines a three-dimensional space (i.e. the construction innovation space).

A systematic process of using administrative decisions, organisation, operational skills and capacities to meet the challenge of planning for, responding to, recovering from and mitigating health consequences of disasters. A decision-making tool that provides information for goal definition, option analysis, consensus-based, informed decision making and ultimately, rapid implementation of priority projects.

A high-level policy tool that focuses on stakeholder coordination, effective communications and shared long-term vision.

A rational methodology for seeking agreement when selecting technologies supporting organisational goals and a framework that may be used for establishing and adjusting technology development time-lines.

SDU (2013) A framework for action to develop a sustainable health system.

Out of the 20 reported definitions, eight describe roadmaps as tools to enable processes, and in particular collaborative planning processes. Nevertheless, there is no common agreement and the term is used loosely to describe: frameworks (three); approaches (two); methods (two); documents (two); processes (one); visual aids (one); and views of stakeholders (one). This may be related to the way in which roadmaps are used, rather than to the structure of the roadmap itself. For instance, Probert and Radnor (2003) in defining roadmap as "the view of a group of stakeholders as to how to get where they want to go to achieve their desired objective" explored a fundamental aspect of roadmaps, precisely communication between different groups of stakeholders and the need to provide flexibility to meet future needs as well as current needs.

Seven out of the 20 definitions suggest that roadmaps should link strategy to operation, thus enabling actions within a wider framework (Groenveld, 1997; Strauss et al., 1998; Kappel, 2001; Wells et al., 2004; Lee and Park, 2005; Kamtsiou et al., 2006; Gerdsri and Kocaoglu, 2007). Froese and Rankin (2009) developed a three-dimensional space (i.e. the construction innovation space), through the combination of: application area, technology, and innovation lifecycle phase. The proposed space allows the development of each dimension.

Three definitions already include suggestions for forecasting approaches to be used when analysing future opportunities in order to develop winning solutions (Kappel, 2001; Petrick 
and Echols, 2004; Rinne, 2004). However, this may be partially valid in the health and social care sector, where future trends may be strongly dependent on past conditions and recent trends. Historical records provide important information upon which future projections can be based. Acknowledging the variation existing among specifications, processes and formats, this research adopts the following working definition.

"A roadmap for health and social care facilities is a tool to: identify the current needs, capabilities and targets against a shared vision for future change; plan and measure the performance; and implement subsequent targets when changes arise."

\section{Data and findings from literature review}

The publications search criteria identified: 74 results in Science Direct; 76 in PubMed; and 83 in Scopus (refined engineering \& environmental sciences). The abstracts were used to identify the articles that were relevant to this study, thus reducing the number to 102 . The full text review confirmed that 48 articles met the search criteria and scope of this work, with an additional 16 retrieved from their individual citations. This resulted in 64 articles being included in this review. Data were extracted and coded per sector (i.e. 11 in the technology sector, and six in the construction sector).

Roadmaps can be used to look at a product (i.e. technology roadmap) or at a process (i.e. issue-oriented), which may result in different specifications and processes for each individual roadmap. Table 2 presents a taxonomy of specifications and processes of roadmaps used in the technology sector (i.e. development of products/processes for technologies) as reported in literature. Time, vision, goals, market and resources appear to be essential specifications for the development of successful roadmaps for products and/or processes. Conversely, the literature search identified several different processes, of which the 'follow-up' is more frequently acknowledged in process-based rather than product-based roadmaps. Table 3 presents a literature-based taxonomy of specifications and processes for roadmaps relating to the construction sector (i.e. development of products/processes for buildings). More recently, the construction sector adopted road-mapping processes and roadmaps in an attempt to: focus on efficiency measures for buildings (Straube, 2005; Singer, 2010), in response to the current economic climate and the reduction in resources availability; and improve business performance (Froese and Rankin, 2009; Kim et al., 2009; Khosrowshahi and Arayici, 2012) through implementation of available strategies and knowledge.

Table 2. Roadmap specifications and processes in technology sector from literature

\begin{tabular}{lllll}
\hline Author (year) & Type & \multicolumn{1}{c}{ Aim } & \multicolumn{1}{c}{ Specifications } & \multicolumn{1}{c}{ Processes } \\
\hline Lee et al. & Product & To seek agreement when & Time, vision, goals, & Planning; demand \\
(2013) & selecting technologies & scope, CSFs, team, & identification; service \\
& supporting & technology, & identification; device \\
& organisational goals, and & performance, customer & identification; \\
& to establish and adjust & demands, customer & technology \\
& technology development & needs, sustainability, & identification; \\
& timelines. & value (use), quality & development; \\
& & standards, availability, & \\
\hline
\end{tabular}




\begin{tabular}{|c|c|c|c|c|}
\hline & & & $\begin{array}{l}\text { applicability, and } \\
\text { security. }\end{array}$ & $\begin{array}{l}\text { adjustment; and follow- } \\
\text { up. }\end{array}$ \\
\hline $\begin{array}{l}\text { Kamtsiou et } \\
\text { al. (2006) }\end{array}$ & Process & $\begin{array}{l}\text { To map out the desired } \\
\text { future for technology- } \\
\text { enhanced professional } \\
\text { learning in the form of } \\
\text { prevalent visions in the } \\
\text { community at large. }\end{array}$ & $\begin{array}{l}\text { Time, vision, team, and } \\
\text { capabilities. }\end{array}$ & $\begin{array}{l}\text { Foresight phase (i.e. } \\
\text { current state and vision); } \\
\text { and planning phase (i.e. } \\
\text { gap analysis, } \\
\text { capabilities, and action } \\
\text { plan). }\end{array}$ \\
\hline $\begin{array}{l}\text { Lee and Park } \\
(2005)\end{array}$ & Process & $\begin{array}{l}\text { To support the strategic } \\
\text { management (i.e. } \\
\text { forecasting, planning, } \\
\text { and administration) of } \\
\text { technology. }\end{array}$ & $\begin{array}{l}\text { Time, business needs, } \\
\text { targets, technology, risk } \\
\text { plan, and environmental } \\
\text { conditions. }\end{array}$ & $\begin{array}{l}\text { Classification (i.e. } \\
\text { purpose and type); } \\
\text { standardisation (i.e. } \\
\text { product and } \\
\text { technology); and } \\
\text { modularization (i.e. } \\
\text { planning, forecasting } \\
\text { and administration). }\end{array}$ \\
\hline $\begin{array}{l}\text { Petrick and } \\
\text { Echols (2004) }\end{array}$ & Process & $\begin{array}{l}\text { To organise data into } \\
\text { meaningful categories } \\
\text { that can be manipulated } \\
\text { both temporarily and } \\
\text { across organisational } \\
\text { functions. }\end{array}$ & $\begin{array}{l}\text { Time, market needs, } \\
\text { resources, risk plan, } \\
\text { capabilities, ROI, trust, } \\
\text { competency, } \\
\text { sustainability, } \\
\text { innovation, } \\
\text { performance, and } \\
\text { information transfer. }\end{array}$ & NP \\
\hline $\begin{array}{l}\text { Phaal et al. } \\
(2004)\end{array}$ & Process & $\begin{array}{l}\text { To support } \\
\text { development, } \\
\text { communication and } \\
\text { implementation of } \\
\text { technology and business } \\
\text { strategy. }\end{array}$ & $\begin{array}{l}\text { Time, socio-technical } \\
\text { change, value, goals, } \\
\text { targets, technologies, } \\
\text { market, resources, } \\
\text { capabilities, ownership, } \\
\text { and communication. }\end{array}$ & $\begin{array}{l}\text { Planning (i.e. market, } \\
\text { product, and } \\
\text { technology); and } \\
\text { customising (i.e. setting } \\
\text { up, managing, and } \\
\text { following on). }\end{array}$ \\
\hline Rinne (2004) & Process & $\begin{array}{l}\text { To formulate future } \\
\text { strategy, to solicit and } \\
\text { justify funding, to } \\
\text { forecast technology and } \\
\text { product changes. }\end{array}$ & $\begin{array}{l}\text { Time, profitability, risk } \\
\text { plan, cost, organisation } \\
\text { capability, feedback, } \\
\text { and audience. }\end{array}$ & $\begin{array}{l}\text { Representation; } \\
\text { communication; } \\
\text { planning; and } \\
\text { coordination. }\end{array}$ \\
\hline $\begin{array}{l}\text { Albright and } \\
\text { Kappel (2003) }\end{array}$ & Product & $\begin{array}{l}\text { To define the plan for } \\
\text { the evolution of a } \\
\text { product, linking } \\
\text { business strategy to the } \\
\text { evolution of the product } \\
\text { features and costs to the } \\
\text { technologies needed to } \\
\text { achieve the strategic } \\
\text { objective. }\end{array}$ & $\begin{array}{l}\text { Time, needs, gaps, } \\
\text { policy, language, } \\
\text { market, product, } \\
\text { technologies, risk plan, } \\
\text { and cost. }\end{array}$ & $\begin{array}{l}\text { Strategy; and action } \\
\text { plan. }\end{array}$ \\
\hline $\begin{array}{l}\text { Albright } \\
(2002)\end{array}$ & Product & $\begin{array}{l}\text { To lay out the evolution } \\
\text { and timing of platform } \\
\text { products to serve } \\
\text { multiple, changing } \\
\text { market segments. }\end{array}$ & $\begin{array}{l}\text { Time, market needs, } \\
\text { priorities, goals, } \\
\text { customer needs, } \\
\text { capabilities, team, } \\
\text { performance, } \\
\text { technology, risk plan, } \\
\text { and cost. }\end{array}$ & $\begin{array}{l}\text { Strategy; and action } \\
\text { plan. }\end{array}$ \\
\hline $\begin{array}{l}\text { Strauss et al. } \\
(1998)\end{array}$ & Product & $\begin{array}{l}\text { To detail } \\
\text { implementation of plans, } \\
\text { converting explicit } \\
\text { inputs and tacit } \\
\text { knowledge into more }\end{array}$ & $\begin{array}{l}\text { Time, market needs, } \\
\text { product attributes, goals, } \\
\text { requirements, priorities, } \\
\text { and evolution plan. }\end{array}$ & $\begin{array}{l}\text { Define content; develop } \\
\text { the product technology } \\
\text { RM; and follow-up } \\
\text { activities. }\end{array}$ \\
\hline
\end{tabular}


Klinckenberg Product To identify precise et al. (2013)

Khosrowshahi Process
and Arayici
(2012)

Froese and Rankin (2009) industry to prepare ladder.

Process To support knowledgeable

\begin{tabular}{lcl}
\hline \multicolumn{2}{l}{ Table 3. Roadmap specifications and processes in } \\
\hline \multicolumn{1}{c}{ Author (year) } & Type & \multicolumn{1}{c}{ Aim } \\
\hline $\begin{array}{l}\text { Bouma et al. } \\
\text { (2015) }\end{array}$ & Process & $\begin{array}{l}\text { To match short-term and } \\
\text { long-term goals with } \\
\text { specific technological } \\
\text { solutions. }\end{array}$ \\
Klinckenberg & Product & $\begin{array}{l}\text { To identify precise } \\
\text { ebjectives and helps } \\
\text { focus resources on the } \\
\text { critical technologies that } \\
\text { are needed to meet those } \\
\text { objectives. }\end{array}$
\end{tabular}

To lay the foundation for the UK construction moving up top maturity decisions (i.e. mental checklist of topics and perspectives) on adoption and implementation of construction innovations.

\author{
Kim et al. Process To significantly improve \\ (2009a)
}

Time, perceived needs, scope, stakeholders, targets, specifications, technologies, and requirements.

Time, market, product, and technology.
Preliminary activity (i.e. scope and specifications); development (i.e. targets, requirements and technologies); and follow-up (i.e. implementation plan).

NP and risks of markets,

usable and
understandable explicit

knowledge. technology investment decisions by identifying technology gaps and requirements. (n) 


\begin{tabular}{|c|c|c|c|c|}
\hline $\begin{array}{l}\text { Robinson et } \\
\text { al. (2006) }\end{array}$ & Process & $\begin{array}{l}\text { To facilitate the } \\
\text { implementation of } \\
\text { knowledge management } \\
\text { strategy in construction } \\
\text { organisations. }\end{array}$ & $\begin{array}{l}\text { Time, goals, business } \\
\text { objectives, leadership, } \\
\text { resources, IT, tools, } \\
\text { implementation plan, } \\
\text { performance, customers, } \\
\text { impact on society (e.g. } \\
\text { pollution, safety, } \\
\text { accidents, and resources } \\
\text { preservation). }\end{array}$ & $\begin{array}{l}\text { Start-up; take-off; } \\
\text { expand; progress; and } \\
\text { sustain. }\end{array}$ \\
\hline
\end{tabular}

A common set of roadmap specifications emerged from the literature, including time, vision, needs, gaps, targets, market, performance, requirements, resources, stakeholders and value/Return on Investment (Velilla et al.). Nevertheless, a closer look at the specific sector and type revealed that additional specifications should also be considered, which may not be valid for a generic roadmap. Klinckenberg et al. (2013) reviewed building renovation roadmaps and policies in the EU member states, Canada and the US, and identified important missing elements: implementation strategies; support by parties involved; analysis of stateof-the-art; and wide focus. This suggests that further work is required to contribute to the development and use of roadmaps for the construction sector and for the wider infrastructure sector including care facilities.

Most authors described a three-step process for the development of roadmaps: preliminary activity; development of the roadmap; and follow-up activity, as initially described by Garcia and Bray (1997). Nevertheless, roadmaps based on a two-step process, which do not include any follow-up plan, have also been produced.

During the development an integrated service-device-technology roadmap, Lee et al. (2013) identified three "critical factors" to the development of integrated roadmaps: lack of layers and sub-layers based on a systematic classification of the subject; no development of appropriate templates to support communication between different groups; and lack of a systematic way to maintain and update roadmaps.

\section{Layers and processes}

Despite the different formats that can be used within roadmaps (Phaal et al., 2001), the literature has demonstrated the importance of structure when developing roadmaps, and in particular the layers and sub-layers. Error! Reference source not found. presents the generic layered structure required to explore opportunities and risks of markets, products and technologies over time, as proposed by the European Industrial Research Management Association (1997). This layout enables planning at macro, meso and micro levels, as recommended by Phaal et al. (2004). The use of multiple layers containing different levels of detail may be a valuable approach when defining resilient and sustainable performance of health and social care facilities as different layers can accommodate details that may be relevant to different stakeholders, to enable sound decisions, thus actions. 


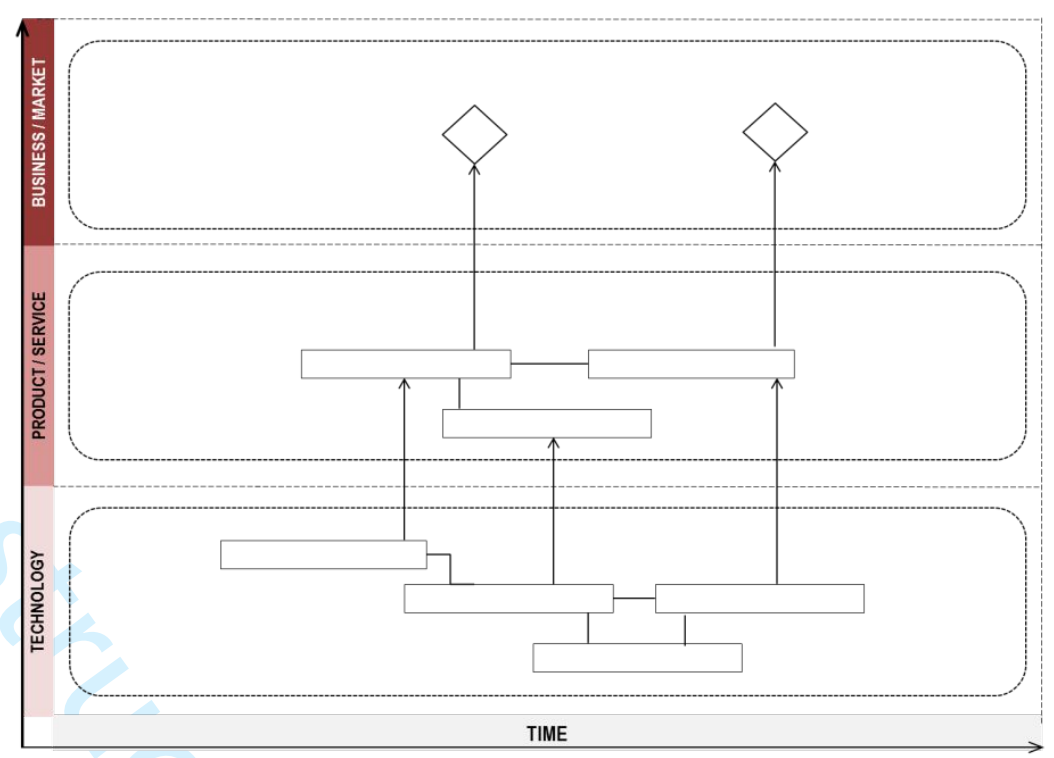

Figure 1. Layered technology roadmap structure adapted EIRMA, 1997

Nevertheless, seven out of the 11 roadmaps analysed in the technology sector did not use layers, and in most cases, did not mention the opportunity to do so in the implementation phase. Only Lee and Park (2005) endorsed the use of layers as they can enhance standardisation, thus relevant to care facilities. From the analysis of the roadmaps in the construction sector, none of the six presented earlier in Table 3 were based on defined layers, which suggests enhancements may be put forward in this sector. Kim et al. (2009a), in their interdisciplinary work, proposed a roadmap at macro level, which included 12 different themes grouped per "value chain" (i.e. planning/design; construction site management; construction robot; modularized construction; maintenance; and new materials). Although these do not correspond to different layers, they support the concept of a structured tool, and layers could be identified in relation to each value chain. A structured approach can thus lead to a common and standardised roadmap that can potentially be adapted to accommodate regional variations among health and social care organisations.

Conversely, most of the analysed work suggested a three-step process to roadmaps. Among the exceptions, Kamtsiou et al. (2006) detailed only a foresight phase (i.e. current state and vision) and a planning phase (i.e. gap analysis, capabilities, and action plan), with no discussion on how to implement the developed plan over time. Strategy and action plan are the two processes identified for the development of roadmaps in the technology sector, where they represent tools to describe future objectives and how these will be achieved (Albright, 2002; Albright and Kappel, 2003). Nevertheless, this results in a poor response to future changes. When looking at the construction sector, to which health and social care facilities belong, the implementation phase is always acknowledged, despite the variation in terminology used. Froese and Rankin (2009) claimed that "a successful innovation life cycle turns something new into something that is standard practice". Hence, roadmaps should be deployed to drive an organisation's strategy into a coherent and shared operational practice across different stakeholder groups. 


\section{Use of roadmaps in the UK}

In the UK, different sectors (e.g. energy, construction, government and healthcare), both private and public, are increasingly promoting the use of roadmaps, especially at strategic level. For instance, the Department of Energy and Climate Change (2013) has had in place a Renewable Energy Roadmap since 2011, to frame the targets and set the actions to deliver renewable energy deployment. The document, which is structured in technology/sectors, has allowed the Government to describe over 200 activities, including achievements, standing activities, barriers to deployments, and timing.

HM Treasury and the Infrastructure Client Group (2014) produced a "Project Initiation Routemap for Improving Infrastructure Delivery", with the aim to improve project performance. The definition of this 'routemap' as an "aid to strategic decision-making” aligns to the definition of roadmaps discussed earlier in this study. This routemap (i.e. roadmap) suggests an objective and systematic approach to strategic decision-making and is organised in a set of assessment tools for: complexity; capability; and alignment for success. These, and their subsets, namely correspond to the three-step process roadmap (i.e. preliminary activity, development of the roadmap and follow-up activity). The "Project Initiation Routemap for Improving Infrastructure Delivery" handbook offers a series of checklists to identify the gaps to enable future plans. This roadmap contains high-level strands that could be potentially valid to enhance project performance of different types of infrastructure, including health and social care.

In its vision to transform NHS services and to improve health outcomes using technology and data, and following the release of the National Information Board's vision document "Personalised Health and Care 2020" (2014), NHS England worked towards detailed plans for the delivery of six work-streams: 1) enable me to make the right health and care choices: supporting digital services for patients and citizens; 2) transforming general practice; 3 ) out of hospital care and integration with social care; 4) acute and hospital services; 5) paper-free healthcare and system transactions; and 6) data for outcomes and research. As a result, six roadmaps were produced for consultation, whose outcomes were expected by the end of 2016 (National Information Board, 2015). This chosen approach demonstrates the need for a systematic and integrated management system, aimed at enabling the process and substantiating the product.

\section{DH policy framework for operational productivity and performance}

In the publication "Five year forward view - Time to deliver", the NHS (2015) established the scope for meeting the needs of future patients in a sustainable way through closing the gaps in: health and wellbeing; care and quality; and funding and efficiency. Far from how the concept of sustainability has been argued and targeted over the past 20 years (Robinson and Cole, 2015), this approach appears to be aligned to the original 1987 definition and includes social and economic dimensions together with the ecological (WCED, 1987).

Health Technical Memoranda (HTM) are technical engineering guidance on healthcarespecific elements of standards, policies and up-to-date established best practice produced by the Department of Health England. HTM 07-07 Sustainable health and social care buildings: 
Planning, design, construction and refurbishment is based on the principle that a building's performance relies on successful actions towards the achievement of sustainability targets at planning, design, procurement and construction stages (Department of Health, 2013). The guidance suggests 10 actions based on the UK government's five principles for sustainable development policy (HM Government, 2005): 1) living with environmental limits; 2) ensuring a strong, healthy and just society; 3) achieving a sustainable economy; 4) promoting good governance; and 5) using sound science responsibility. It also includes advice on possibilities for sustainable refurbishment of health and social care buildings.

Health Building Notes (HBNs) are best practice guidance on the design and planning of new healthcare buildings and on the adaptation and/or extension of existing facilities produced by the Department of Health England. HBN 00-07 Planning for a resilient healthcare estate is based on a business continuity (i.e. maintain clinical services) approach which integrates buildings, infrastructure and service resilience to emergencies, hazards and threats (Department of Health, 2014). The guidance also refers to responding to surge capacity, thus meeting increased demands for clinical care. This guidance recommends that risk assessment plans should include a hazard-and-threat analysis as part of the decisionmaking process.

Five out of the seven objectives set by the Government in the NHS England mandate for 2016-17 strongly relate to the built environment: to help create the safest, highest quality health and care service; to balance the NHS budget and improve efficiency and productivity; to maintain and improve performance against core standards; to improve out-of-hospital care; and to support research, innovation and growth (DH, 2016). However, the current economic climate and the reduction in resources availability are boosting the focus on efficiency measures for buildings (Straube, 2005; Singer, 2010).

In its effort to enhance operational productivity and performance in English NHS acute hospitals, the Department of Health (DH) England in 2014 started a journey that has led to an independent review on how efficiencies can be achieved by 2020 (Lord Carter of Coles, 2016). The investigation conducted initially among a cohort of 22 NHS non-specialist acute trusts and subsequently expanded to 32 trusts revealed the extensive variation that is present nationally in health service provision (e.g. hospital estate, workforce, procurement, treatment cost, pathology, and orthopaedics). Initially, four areas with efficiency opportunities were identified: workforce; hospital pharmacy and medicines optimisation; estates management; and procurement (Lord Carter of Coles, 2015). The in-depth analysis led to 15 recommendations for NHS trusts that include: a national strategy for the entire system; benchmarks for specific departments; joint clinical governance among the different parties; targets for efficiency and productivity improvements; and an integrated performance framework across health and social care regulatory bodies (i.e. CQC and NHS England).

\section{Data and findings from research streams}

Resilience and sustainability are addressed from a broader perspective within their "natural environment", as such multiple driving factors are captured from recent research streams that responded to the following criteria: conducted on UK health and social care facilities; and 
included multiple case studies. The data gathered out of each research stream led to the identification of research-specific drivers; and content analysis captured key issues within each research stream. The identified issues were further explored and then compared across the three research streams, leading to the identification of three layers: organisation, infrastructure, and process. The identified issues are summarised below.

\section{Research stream 1: Backlog Maintenance and Critical Infrastructure Risk in NHS acute} trusts

This theme of research explored issues related to Backlog Maintenance and Critical Infrastructure Risk in NHS acute trusts. The detailed results of this work have been presented in Mills et al. (2015) and Pantzartzis et al. (2016a), thus available for consultation. The work was commissioned by the DH England in an effort to evaluate the condition of critical (i.e. high and significant risks) backlog maintenance within the NHS and identify appropriate levels of investment to ensure that critical backlog does not accumulate. The identified drivers were: the costs of asset management in NHS acute trusts; the economic constraints due to depreciation and obsolescence of existing assets; the call for a sustainable future (e.g. energy performance; resources and waste reduction); and the risks posed onto patients, visitors and staff. The review of the NHS acute trusts' assets included: quantitative analysis of national datasets for 115 trusts, and qualitative analysis of seven interviews with selected trusts. The analyses captured the issues presented below.

Knowledge - Knowledge of acute trust's assets is the starting point towards putting forward an integrated strategy. Methods to gather this knowledge and potentially share best practice among peers are not currently available. Different NHS acute trusts are operated differently (e.g. Private Finance Investment schemes are managed differently), thus a common structure that can allow to build be-spoke operational strategies might result a sustainable opportunity. The age of buildings in NHS acute trust's estates exposes each organisation to higher pressures of resources allocation, in a time in which national economy was already under public scrutiny. This impacts financial performance, depending on the initial financial position of each trust, nonetheless the age of the buildings proved that could be used as: a proxy for critical infrastructure backlog and building condition; and a proxy for cost maintenance, depreciation and performance (Mills et al., 2015).

Investment strategies - Despite the estates' conditions, the approach maintained by the Trusts revealed an actual spend (i.e. percentage of income spent) significantly lower than the total estimated backlog cost, with consequent potential long-term increasing risks to patients, visitors and staff. In some circumstances, this may be part of a long-term strategy towards decommissioning, demolition or sale of the estate assets, nevertheless regular investments can more effectively keep the levels of backlog low, thus increasing safety and quality of the built assets.

Performance metrics - Detection and prevention of backlog appeared to be associated to the methodology in use, which in some occasions did not fully support the needs of the trusts. The variation present among the NHS acute trusts, within each trust, and within each trust site raised issues relating to the need for additional guidance and more flexible solutions. The 
lack of a shared set of performance metrics to capture levels of backlog maintenance makes it difficult to develop integrated actions within and across organisations, from which wider understanding could be developed and implemented.

Service delivery strategies - Health service delivery and service development strategies emerged during the research study as not always being well aligned. However, the qualitative analysis of interviews reported successes, where organisations were able to align these strategies. Sustainable management of backlog maintenance in NHS acute trusts cannot be delivered if not with planned investments over long-term timeframes, matching service delivery strategies to maximise the outcomes.

\section{Findings from Research Stream 1}

Research Stream 1 demonstrated the DH's intention to improve the national building portfolio, whose economic and environmental performance is no longer sustainable. The issues presented fall into three main categories: those belonging to the organisation (i.e. culture, knowledge, accountability and assurance); those relevant to the infrastructure (i.e. age of the buildings, maintenance and level of investments); and those relevant to the process (i.e. performance metrics, methodology and data collection and management). In order to respond to critical levels of backlog maintenance, which pose risks onto patients, visitors and staff, a long-term approach is needed.

\section{Research Stream 2: issues on dementia-friendly design of health and social care} environments in England

The 12-month project, "Improving the environment of care for people with dementia" and funded by the DH's Dementia Capital Investment Fund aimed at creating custom-designed care facilities for people living with dementia in health and social care environments. A summary of the results can be accessed on-line through the Gov.UK website and the Project Evaluation Report (Department of Health, 2015) is available on request.

The work was commissioned by the DH England to: improve care environments for people living with dementia by conducting a series of national pilot projects led by NHS (health care) and Local Authorities (LA) (social care); gather evidence and findings from those projects; and inform the development of national best practice guidance. The main driver was the increasing pressure of older people living with long-term chronic conditions (i.e. dementia) on the health and social care assets, and more widely on the entire community environments. The project included 42 NHS provider led (health care) and 73 Local Authority led (social care) pilot projects, which provided the data for the analysis. The analysis revealed the issues below described.

Stakeholder engagement and organisational culture - Stakeholder engagement and organisational culture played a crucial role in determining the success of this project, which implemented: communication; knowledge sharing; and co-operation within and across individual participant organisations. Strong leadership and empowerment schemes were promoted by the participant organisations, which proved to be key in driving the change in the organisational culture. 
Impact of the built environment on the QoL and health outcomes - The impact of the built environment on the Quality of Life (QoL) and health outcomes of people living with dementia is such that future improvements in the environments should be panned and designed "with the person in mind". People living with dementia may experience different impairments, in relation to the type and level of dementia (e.g. Alzheimer, Lewy bodies), thus this is no obstacle to a person-centred environment of care. Different design-solutions may be best suited to improve different types of settings (i.e. health and social), of spaces (i.e. indoor and outdoor, individual and communal), and can respond to individual organisation's capital availability and strategic plans.

Technological innovation - Health and social care organisations have promoted the use of technological innovations to implement the QoL of people living with dementia (i.e. patients and residents) but also the QoL of their formal (i.e. health and social care staff) and informal (i.e. family and friends) carers. Besides the introduction of new technologies (e.g. LED lighting and video-calling systems) may offer the opportunity to also contain the costs. Investment strategies - Health and social care organisations present considerable differences in terms of organisation, infrastructure and processes. The size and type of the estate are different, thus presenting different challenges. Different capital availability might be reflected in the investment strategies adopted many of which can be low cost but high impact, for example: routine maintenance offers many opportunities to invest in innovative planning and design solutions, which then would be trialled at very little extra cost.

Performance metrics and data driven-solutions - Performance metrics need to consider the variability between health and social care estate assets, which encompass both the built environment and the service provision. Only effective comparison with peer facilities can enable the implementation of performance. Performance metrics are essential to data-driven approaches, to deliver evidence-based solutions for the built environment.

Person-centred and integrated care delivery strategies - The diversity of settings involved demonstrated how an effective service provision should rely on a combination of health and social care settings linked though an integrated service plan, to improve the QoL of people living with dementia (i.e. patients and residents), but also the QoL of their formal (i.e. health and social care staff) and informal (i.e. family and friends) carers. Person-centred approaches are needed to put in place resilient service delivery strategies, which can prove more effective than generic health and/or social care approaches.

\section{Findings from Research Stream 2}

Research Stream 2 gathered evidence on the impact of the built environment on people living with dementia at national level, subsequent to physical interventions on the built environment. An ageing population and its related conditions, among which dementia, have called upon resilience of the entire health and social care system, that is not-fit-for purpose. Also in this case, the issues discussed fall into the main headings: organisation (i.e. awareness, communication, culture, engagement and training); infrastructure (i.e. building components, settings and spaces); and process (i.e. guidance, performance metrics and data). 
Research Stream 3: Issues on operational productivity and performance in English NHS acute hospitals

The "Operational productivity and performance in English NHS acute hospitals" stream supported the improvement of English NHS Trusts' operational productivity and performance based on an analysis on one of the elements with capacity for improvement suggested by the Lord Carter review: "estates and facilities management". In particular, two key elements are included: space utilisation; and energy consumption. Across the NHS estate "cost drivers can vary widely due to the size, age, and condition of buildings, and local delivery models" (Lord Carter of Coles, 2016). Space utilisation and energy consumption are two elements that may drive potential cost reduction through achieving the set benchmarks by April 2017. The research identified the following issues.

Space utilisation: clinical and non-clinical spaces - Space utilisation refers to space capacity, but also type and location in relation to the capability to optimise its use. Resilience can be achieved through a correct management of space utilisation, which can be reduced, by means of selling or renting owned space, or increased, by means of buying or renting new space. The work conducted highlighted issues around the definition of clinical and nonclinical spaces within the acute organisations, which directly link into space utilisation rates. This aspect should contribute to resolving discrepancy between size of the built assets and service provision levels.

Built asset strategies - Mergers and acquisitions can play an important role in the improvement of sustainability of the health infrastructure and drive resilience in health and social care facilities, where the response to the needs should drive the service provision. Such actions can be possible when a strategy is in place, but also when operational processes are in place to deliver the strategy. Appropriate frameworks to support those processes need to be developed to encourage communication between different groups (e.g. chief executives and facilities managers).

Investment strategies - Lord Carter (2016) suggested potential areas of savings such as: LED lighting; combined heat and power units; and smart energy management system. To identify those savings, which will impact on a reduction of carbon emissions as well, there is a need to comprehend the reasons behind the "unwanted variations" reported in the report. Different trusts have different strategies, which are not always built into the "costing reporting system", leaving open gaps in data collection and reporting, thus in measuring the performance of the health care organisation.

\section{Findings from Research Stream 3}

Research Stream 3 represented nation-wide effort to put in place a methodology capable to build upon regional and local variations, thus setting up valid benchmarks for organisation's strategy development. The operational productivity and performance does not respond to sustainability criteria and may well not be able to cope with future hazards. Levels of energy consumption and space utilisation are no longer sustainable, thus calling for immediate action. The focus is on: organisation (i.e. knowledge, accountability, and communication); 
infrastructure (i.e. space capacity, and space utilisation); and process (i.e. data gathering, energy, performance metrics, and service delivery).

Layers and sub-layers

Most aged built assets are not economically and environmentally sustainable, due to the excessive costs of maintenance and upgrading. They can also create risks for patients, visitors and staff as they are not fit-for-purpose. The variability in age profile and typology of existing buildings determines operational issues which directly impact on their resilience to service provision. Planned investments on elements of the built environment can enhance the resilience of health and social care facilities to change in demand for service provision. Fitness-for-purpose can be achieved by progressive steps through the life of an organisation, but a tool needs to guide the stakeholders through a joint effort. Space capacity and utilisation, together with preventive maintenance can extend the service life of buildings, thus providing resilience and sustainability for existing built assets. Data collection and management systems are required to monitor the actual against the planned performance of health and social care assets, thus allowing operational changes if performance changes. The issues emerged from the three research streams have generated three layers: organisation, infrastructure, and process. Error! Reference source not found. summarises those issues against the identified layers, thus creating a set of sub-layers that can be exploited to populate the proposed roadmap structure. This initial set of sub-layers, which add variable levels of details, can be designed to enable different stakeholders gaining the relevant information to optimally perform the planned action, so that other stakeholders can perform their actions too, supporting communication between different groups, thus enhancing group strengths. The roadmap will facilitate recording of approved decisions and planned actions, thus enabling systematic control of the facility and allow decision-makers to estimate the optimum solution across the estate system.

Table 4. Emerging sub-layers for resilient and sustainable performance

\begin{tabular}{|c|c|c|c|}
\hline Layer & Research Stream 1 & Research Stream 2 & $\begin{array}{l}\text { Research Stream } \\
3\end{array}$ \\
\hline \multirow{8}{*}{ Organisation } & Accountability & & Accountability \\
\hline & Assurance & & $x^{2}$ \\
\hline & & Awareness & 2 \\
\hline & & Communication & Communication \\
\hline & Culture & Culture & 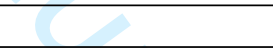 \\
\hline & & Engagement & 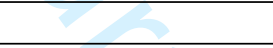 \\
\hline & Knowledge & & Knowledge \\
\hline & & Training & 20 \\
\hline \multirow{8}{*}{ Infrastructure } & Age of buildings & & 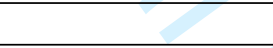 \\
\hline & Building components & Building components & \\
\hline & & Building spaces & \\
\hline & Investment & Investment & \\
\hline & Maintenance & & \\
\hline & & Space capacity & Space capacity \\
\hline & & Space location & Space location \\
\hline & & & Space utilisation \\
\hline \multirow{2}{*}{ Process } & Data gathering & & Data gathering \\
\hline & Data management & Data management & Data management \\
\hline
\end{tabular}




\section{Discussion}

\section{Health and social care priorities}

The global panorama of economic, geopolitical, societal and technological risks to the built environment, apply to health and social care facilities. Current pressures that threaten the operational productivity and performance of English NHS acute hospitals are strongly interconnected with the international trends in ageing population, re-thinking the model of care, changing technologies and decreasing resources (i.e. natural and man-made). The UK health and social care system is not yet ready to manage the change: strategies are in place, but they require metrics and tools to become operational. Moreover, stakeholders' action is needed for the implementation of resilience and sustainability at local level. The priorities set by the government agenda for operational productivity and performance of the acute trusts in England led to the understanding that action is required on the built infrastructure.

The above issues presented play an important role in the resilience and sustainability of the built environment. Demographic changes and ageing populations will put more pressure on the need for service provision (Pantzartzis et al., 2016b), which leave decision-makers in urgent need to put in place actions to manage the built assets and deliver a resilient and sustainable response to changes in demographics, technologies, diseases and models of care.

The three research streams upon which this paper draws raise issues relevant to the entire care system and may have been exacerbated by the non-aligned actions between service provision strategies and asset management. The performance of health and social facilities needs to consider the facilities and all those elements that contribute to the service provision besides only built assets. The performance of an estate may be resilient when the built assets remain safe, effective and operational. But the definition of resilience in the current context shall not only encompass aspects related to engineering (Leveson et al., 2006). Equally, the definition of sustainability shall not any longer be limited to environmental aspects (WCED, 1987). Economic, geopolitical, societal and technological threats require a more comprehensive and integrated response.

\section{A roadmap for resilience and sustainability: layers and processes}

The research demonstrated how different factors should be considered to target resilience and sustainability of care facilities. It also demonstrated how these factors can be projected into layers and processes of roadmaps to develop an effective tool. Figure 2 describes the layers and processes of a roadmap for resilience and sustainability of health and social care facilities, namely organisation, infrastructure and process. 
Figure 2. Roadmap for resilience and sustainability of health and social care facilities: layers and processes

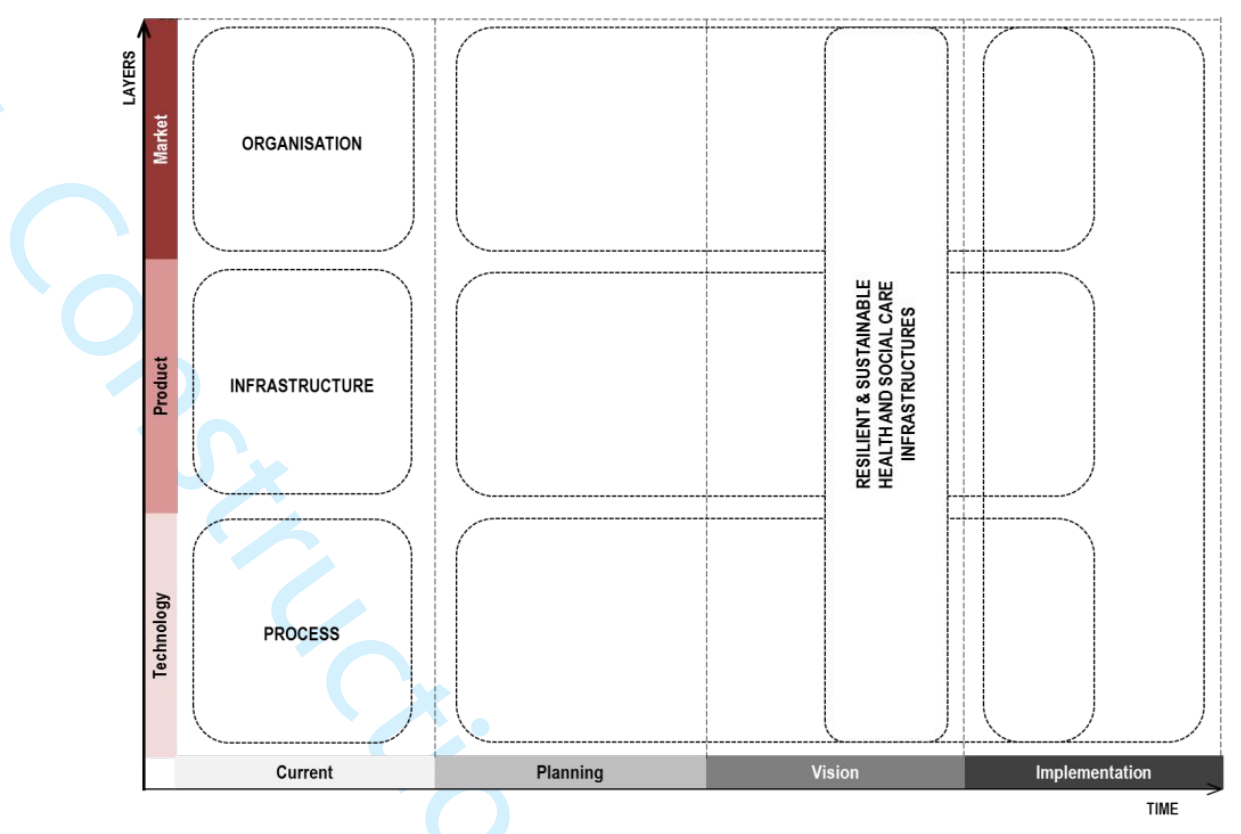

The scope of the roadmap is to: monitor current performance; plan the future actions against defined targets; and put in place technologies to achieve the targets.

The authors suggest a three-layer roadmap, adapting the original 1997 model. Market, product, and technology are vital elements of the health and social care estate, and they equally represent different levels of actions. Any strategy should be endorsed at managerial level, and subsequently at organisation level: culture, accountability and leadership need to be addressed.

The authors propose a four-step process roadmap, in line with the literature presented.

1. Understanding the current conditions. Monitoring the current performance is among the DH priorities in terms of feasibility and impact on the operational efficiency of the system. Even though systems are not yet in place, a strong demand for solutions at managerial level suggests the potential applicability of roadmaps.

2. Planning to achieve the vision. Planning for the future is key in the health and social care sector, and the UK makes no exception. The desire to contain costs in a climate of increasing service demand and change of model of care asks for solutions that can look at accommodating those changes.

3. Achieving the vision. Common goals and clear targets are essential to develop resilient and sustainable health and social care facilities. Life cycles of technology, care models, and built asset life cycles should be reconciled.

4. Implementing the condition over time. Performance implementation can take place only if an operational plan, with templates and guidance, is in place. Culture, knowledge and engagement are strong factors within an organisation's perspective that can contribute to the implementation process.

In order to develop a three-layer, four-step process roadmap, stakeholders should start to take action from the identification of future goals and targets, which may be shared within the 
entire organisation or among different groups of stakeholders. A clear timeframe is essential, thus knowledge and understanding of the current condition becomes a priority. After the identification of clear targets, it is necessary to identity strengths and weaknesses (i.e. threats and opportunities) in pursuing a goal. This planning phase requires a thoroughly knowledge and understanding of the existing assets that may well include ownership of the same organisation in different locations. Building capacity and space utilisation offer opportunities to implement resilience and sustainability, according to specific circumstances that an organisation may experience at a particular time. Shared tools and metrics need to be put in place to record and monitor the performance of the built assets, so that implementation strategies can be deployed. The roadmap recommends processes (i.e. layer three) to manage the property: set of metrics, which may be developed to reflect regional variations, and implementation guidance should be also considered.

\section{Conclusions}

The current economic, geopolitical, societal and technological changes create new challenges for the complex health and social care facilities. As challenges arise, actions will be required prior to any change to improve resilience and sustainability of care facilities. Resilience and sustainability address different issues but are complementary. Many of the challenge are not being addressed in an integrated way. Some researches focus on single issues (e.g. energy or adaptability to models of care). The NHS 10 years plan (i.e. 2019-2029) is emerging and the engagement phase is currently taking place; though it tends to focus on service provision rather than on the estate, leaving space for action. No tool which takes a long-term perspective currently exists. In many infrastructure sectors, roadmaps have proven to be useful tools to monitor performance, set targets, define technology and achieve the targets. However, there are no operational examples of how to develop a roadmap for improving the resilience and sustainability of care facilities. This paper provides an example of how to structure layers and processes to develop a roadmap specifically targeted at achieving resilient and sustainable care facilities, within the UK's long-term agenda. The proposed layered structure offers the opportunity to share the knowledge across organisations, hence the national health and social care system, still leaving the opportunity to tailor the roadmap to respond to the specific needs of individual organisations.

Roadmaps have been effectively deployed in different sectors over the years, providing a wide range of experiences that can be transferred and adapted to the health and social care sector. Evidence from their development in the construction sector has substantiated a potential three-layer structure made of a four-step process.

Roadmaps are powerful tools that can be developed and tailored for a specific organisation, while a common structure can allow different groups of stakeholders to record, monitor and implement opportunities for resilient and sustainable health and social care facilities. They represent a financial, social, environmental and technological viable solution to the continuous changes in health and social care service provision. For example, they can enable continuous monitoring of an organisation's built assets, so that when capacity is reduced, alternative opportunities can be identified within a short-time frame. Conversely, 
they can allow strategic decisions over a longer period, when an organisation may choose to rent out, sell, or buy additional assets to reduce or increase service provision.

The proposed layers are: organisation, infrastructure, and process. Each of them will include a set of sub-layers that shall be identified by individual organisations to implement their resilience and sustainability against future change. At organisational level, culture change, knowledge sharing, service integration and design innovation are powerful elements for change management and can enhance the performance of health and social care facilities, leading to a more sustainable management of the organisation. At infrastructure level, datadriven and person-centred approaches will be more often required to respond to new social, technological, environmental and economic pressures. At process level, systems for data gathering, recording, managing and sharing shall be put in place to enable changes in operations (i.e. service provision).

This work identified a gap between theory and practice, envisioned a more integrated development of service provision and infrastructure asset management, thus identified layers and processes for future implementation, so that roadmaps can be effectively developed and used by multiple stakeholders.

\section{Limitations and way forward}

This research has studied the UK context to provide a specific example from which to derive potential layers and processes for a roadmap for health and social care facilities. This needs to be acknowledged as a limitation. This work does not aim to be exhaustive; on the contrary it aims at initiating a (Bloomfield and Best) practice in response to a discussion that has already started. More work is needed, particularly towards defining what are the criteria to which a resilient and sustainable (health and social) care infrastructure should respond. Resilience and sustainability of the health and social care facilities may reside in complex sets of factors, which need to be precisely identified, and which can further originate sublayers, with different level of customised details to improve resilience and sustainability across the estate's built assets.

\section{Acknowledgments}

This paper describes different streams of research that have been completed with funding by the Engineering and Physical Sciences Research Council (EPSRC), the Health and Care Infrastructure Research and Innovation Centre (HaCIRIC), and the Department of Health England. 


\section{References}

Achour, N. and Price, A. D. F. (2010), "Resilience strategies of healthcare facilities: present and future", International Journal of Disaster Resilience in the Built Environment, 1, 3, 264-276.

Albright, R. E. (2002), "How to use roadmapping for global platform products", PDMA visions, 26.

Albright, R. E. and Kappel, T. A. (2003), "Technology roadmapping: roadmapping the corporation", Research technology management, 46, 2, 31.

Ardalan, A., Rajaei, M. H., Masoumi, G., Azin, A., Zonoobi, V. and Sarvar, M. (2012), "2012-2025 Roadmap of IR Iran's Disaster Health Management", PLoS currents, 4.

Benbasat, I., Goldstein, D. K. and Mead, M. (1987), "The Case Research Strategy in Studies of Information Systems", MIS Quarterly, 11, 3, 369-386.

Bloomfield, B. P. and Best, A. (1992), "Management consultants: systems development, power and the translation of problems", Sociological Review, 40.

Bosher, L., Carrillo, P., Dainty, A., Glass, J. and Price, A. (2007), "Realising a resilient and sustainable built environment: towards a strategic agenda for the United Kingdom", Disasters, 31, 3, 236-255.

Bouma, H., van Rest, J., van Buul-Besseling, K., de Jong, J. and Havekes, A. (2015), "Integrated roadmap for the rapid finding and tracking of people at large airports", International Journal of Critical Infrastructure Protection.

Brown, R. and O'Hare, S. (2001), "The use of technology roadmapping as an enabler of knowledge management".

Cepeda Carrión, G., Luis Galán González, J. and Leal, A. (2004), "Identifying key knowledge area in the professional services industry: a case study", Journal of Knowledge Management, 8, 6, 131-150.

Crowley, P. and Lipschutz, L. N. (2013), Mapping out goals, Inside Healthcare.

Curtis, L. and Burns, A. (2015), Unit costs of Health and Social Care 2015, University of Kent.

Denzin, N. K. and Lincoln, Y. S. (2011), The SAGE handbook of qualitative research, SAGE, London.

Department of Energy \& Climate Change (2013), "UK Renewable Energy Roadmap Update 2013", available at: https://www.gov.uk/government/publications/uk-renewable-energy-roadmapsecond-update [Accessed 27 November 2015].

Department of Health (2013), "Health Technical Memorandum 07-07: Sustainable health and social care buildings: Planning, design, construction and refurbishment", 62.

Department of Health (2014), "Health Building Note 00-07: Planning for a resilient healthcare estate".

Department of Health (2015), Improving the environment of care for people with dementia. Project Evaluation Report. , Department of Health.

DH (2016), The government's mandate to NHS England for 2016 to 2017, Department of Health, Eisenhardt, K. M. (1989), "Building Theories from Case Study Research", Academy of Management Review, 14, 4, 532-550.

European Industrial Research Management Association (1997), Technology Roadmapping: Delivering Business Vision, EIRMA,

Francis, R. (2013), Report of the Mid Staffordshire NHS Foundation Trust Public Inquiry, London.

Froese, T. and Rankin, J. H. (2009), "Strategic roadmaps for construction innovation: assessing the state of research", Journal of Information Technology in Construction (ITcon), 14, Special Issue Next Generation Construction IT: Technology Foresight, Future Studies, Roadmapping, and Scenario Planning, 400-411.

Gabriel, C. and David, M. (2005), "A review of case studies publishing in Management Decision 2003 - 2004: Guides and criteria for achieving quality in qualitative research", Management Decision, 43, 6, 851-876.

Garcia, M. L. and Bray, O. H. (1997), Fundamentals of Technology Roadmapping, Albuquerque, New Mexico, Sandia National Laboratories. 
Gerdsri, N. and Kocaoglu, D. F. (2007), "Applying the Analytic Hierarchy Process (AHP) to build a strategic framework for technology roadmapping", Mathematical and Computer Modelling, 46, 7, 1071-1080.

Groenveld, P. (1997), "Roadmapping integrates business and technology", Research technology management, 40, 5, 48.

Haddad, C. R. and Uriona Maldonado, M. (2017), "A functions approach to improve sectoral technology roadmaps", Technological forecasting and social change, 115, Supplement C, 251-260.

HM Government (2005), Securing the future - delivering UK sustainable development strategy., The Stationery Office,

HM Treasury (2014), "Improving Infrastructure Delivery: Project Initiation Routemap Handbook", available at: https://www.gov.uk/government/publications/improving-infrastructuredelivery-project-initiation-routemap [Accessed 27 November 2015].

Kamtsiou, V., Naeve, A., Stergioulas, L. K. and Koskinen, T. (2006), "Roadmapping as a knowledge creation process: The PROLEARN roadmap", Journal of Universal Knowledge Management, $1,3,163-173$.

Kappel, T. A. (2001), "Perspectives on roadmaps: how organizations talk about the future", Journal of Product Innovation Management, 18, 1, 39-50.

Keogh, B. (2013), Review into the quality of care and treatment provided by 14 hospital trusts in England: overview report, NHS.

Khosrowshahi, F. and Arayici, Y. (2012), "Roadmap for implementation of BIM in the UK construction industry", Engineering, Construction and Architectural Management, 19, 6, 610-635.

Kim, C., Kim, H., Han, S. H., Kim, C., Kim, M. K. and Park, S. H. (2009a), "Developing a technology roadmap for construction R\&amp;D through interdisciplinary research efforts", Automation in Construction, 18, 3, 330-337.

Kim, C., Kim, H., Han, S. H., Kim, C., Kim, M. K. and Park, S. H. (2009b), "Developing a technology roadmap for construction R\&D through interdisciplinary research efforts", Automation in Construction, 18, 3, 330-337.

Klinckenberg, F., Forbes Pirie, M. and McAndrew, L. (2013), Renovation roadmaps for buildings, London Eurima.

Lee, J. H., Phaal, R. and Lee, S.-H. (2013), "An integrated service-device-technology roadmap for smart city development", Technological forecasting and social change, 80, 2, 286-306.

Lee, S. and Park, Y. (2005), "Customization of technology roadmaps according to roadmapping purposes: Overall process and detailed modules", Technological forecasting and social change, 72, 5, 567-583.

Leveson, N., Dulac, N., Zipkin, D., Cutcher-Gershenfeld, J., Carroll, J. and Barrett, B. (2006), "Engineering resilience into safety-critical systems", Resilience Engineering-Concepts and Precepts. Ashgate Aldershot, 95-123.

Lord Carter of Coles (2015), Review of Operational Productivity in NHS providers. Interim Report., Department of Health.

Lord Carter of Coles (2016), Operational productivity and performance in English NHS acute hospitals: Unwarranted variations, Department of Health.

Manyena, S. B. (2006), "The concept of resilience revisited", Disasters, 30, 4, 434-450.

Mills, G. R. W., Deka, L., Price, A. D. F., Rich-Mahadkar, S., Pantzartzis, E. and Sellars, P. (2015), "Critical infrastructure risk in NHS England: predicting the impact of building portfolio age", International Journal of Strategic Property Management, 19, 2, 159-172.

National Information Board (2015), "Delivering the Five Year Forward View. Personalised Health and Care 2020", available at: https://www.gov.uk/government/publications/implementingpersonalised-health-and-care-2020 [Accessed 27 November 2015].

NHS (2014), Five Year Forward View, NHS England.

NHS (2015), Five Year Forward View - Time to deliver, NHS England.

NHS (2019), The NHS Long Term Plan, NHS England. 
NIB and Department of Health (2014), "Personalised health and care 2020", available at: https://www.gov.uk/government/publications/personalised-health-and-care-2020 [Accessed 27 November 2015].

Nirupama, N., Popper, T. and Quirke, A. (2015), "Role of social resilience in mitigating disasters", International Journal of Disaster Resilience in the Built Environment, 6, 3, 363-377.

Pantzartzis, E., Deka, L., Tann, C., Mills, G. R., Mahadkar, S. and Price, A. D. F. (2016a), "Sustainable management of NHS assets backlog maintenance", Built Environment Project and Asset Management, accepted.

Pantzartzis, E., Price, A. D. F. and Pascale, F. (2016b), "A built environment response to the rising costs of dementia", Journal of Financial Management of Property and Construction, 21, 2.

Petrick, I. J. and Echols, A. E. (2004), "Technology roadmapping in review: A tool for making sustainable new product development decisions", Technological forecasting and social change, 71, 1, 81-100.

Phaal, R., Farrukh, C. and Probert, D. (2001), "Technology Roadmapping: linking technology resources to business objectives", Centre for Technology Management, University of Cambridge, 1-18.

Phaal, R., Farrukh, C. J. and Probert, D. R. (2004), "Technology roadmapping-a planning framework for evolution and revolution", Technological forecasting and social change, 71, 1, 5-26.

Probert, D. and Radnor, M. (2003), "Technology roadmapping: frontier experiences from industryacademia consortia", Research technology management, 46, 2, 27.

Rinne, M. (2004), "Technology roadmaps: Infrastructure for innovation", Technological forecasting and social change, 71, 1-2, 67-80.

Robinson, H. S., Anumba, C. J., Carrillo, P. M. and Al - Ghassani, A. M. (2006), "STEPS: a knowledge management maturity roadmap for corporate sustainability", Business Process Management Journal, 12, 6, 793-808.

Robinson, J. and Cole, R. J. (2015), "Theoretical underpinnings of regenerative sustainability", Building Research \& Information, 43, 2, 133-143.

Rogers, P. (2015), "Researching resilience: An agenda for change", Resilience, 3, 1, 55-71.

Singer, B. C. (2010), High Performance Healthcare Buildings: A Roadmap to Improved Energy Efficiency.

Straube, B. (2005), "The CMS Quality Roadmap: quality plus efficiency", Health Affairs, 24, W5.

Strauss, J., Radnor, M. and Peterson, J., "Plotting and navigating a non-linear roadmap: knowledgebased roadmapping for emerging and dynamic environments", Proceedings of the East Asian Conference on Knowledge Creation Management,6-7.

Sustainable Development Unit (2013), Route map for sustainable health, Cambridge, Sustainable Development Unit

UNISDR (2005), Hyogo Framework for Action 2005-2015: Building the Resilience of Nations and Communities to Disasters, United Nations International Strategy for Disaster Reduction.

UNISDR (2015), Sendai Framework for Disaster Risk Reduction 2015-2030, United Nations International Strategy for Disaster Reduction.

United Nations (2015a), The Millennium Development Goals Report 2015, In: Way, C. (ed.), New York, United Nations.

United Nations (2015b), Transforming our world: the 2030 Agenda for Sustainable Development, United Nations,

Velilla, N. M., Bouzon, C. A., Contin, K. C., Beroiz, B. I., Herrero, Á. C. and Renedo, J. A. (2012), "Different Functional Outcomes in Patients with Delirium and Subsyndromal Delirium One Month after Hospital Discharge", Dementia and Geriatric Cognitive Disorders, 34, 5-6, 332336.

Vishnevskiy, K., Karasev, O. and Meissner, D. (2015), "Integrated roadmaps and corporate foresight as tools of innovation management: The case of Russian companies", Technological forecasting and social change, 90, Part B, 433-443. 
WCED (1987), Our Common Future, Oxford, United Nations.

Wells, R., Phaal, R., Farrukh, C. and Probert, D. (2004), "Technology roadmapping for a service organization", Research technology management, 47, 2, 46.

World Economic Forum (2015), Global Risk 2015, 10th ed., Geneva, World Economic Forum.

Zhong, S., Clark, M., Hou, X. Y., Zang, Y. L. and Fitzgerald, G. (2014), "Proposing and developing a definition and conceptual framework for health care resilience to cope with disasters", Emergencias, 26, 69-77. 
Referee: 1

Recommendation: Minor Revision

\section{Comments:}

Review Round 2:

It is good to see that authors have taken great effort to address the reviewers' comments. I further expect further improvements;

1. It is good to mention research objectives, just after the research aim.

This revision has been made in full. The research objectives have been mentioned after the research aim, at the end of the paragraph titled "Introduction" and the text has been rephrased to improve readability.

2. Details discussed under research methodology should be revised as follows;

a. "Roadmap: a working definition" can be shifted under Literature section

This revision has been made. The authors confirm to the Reviewer that the paragraph that develops the working definition contains literature review, however they wish to keep separate the literature that relates to the definition of roadmap from the literature that relates to the structure and type of roadmaps, hence they have chosen to amend the title of the paragraph to "Roadmap: a working definition from literature review".

b. The second paragraph from page 4 line 26 up to line 40 is more appropriate under literature as it gives literature on "construction of technical roadmap"

This revision has been partially made. The authors have introduced the text to which the Referee makes reference in response to review Round 1. The mentioned line 26-40 are literature review indeed, but they support the choice of the research methodology and specifically why the authors have used multiple research streams to develop one roadmap.

c. Sub-heading starting from page 7 up to the heading "data and findings from research streams", under Research methodology are more appropriate under Literature review.

The authors wish to clarify that the sub-headings to which the Referee makes reference are not literature review, but are the data and the data findings out of the three separate research streams used to develop the manuscript. The authors wish to make reference to the methodology used, which combines literature review of published material and data findings from research streams that the authors have completed over the past years, and that all relate to the same area of research.

The authors wish to thank the Referee for the positive feedback and the further changes recommended, which have been considered to improve readability, consistency and quality of the manuscript.

The responses are reported below each comment.

Additional Questions:

$<b>1$. Originality: $</ b>$ Does the paper contain new and significant information adequate to justify publication?: Yes.

The authors thank the Referee for acknowledging the originality of this work.

$<b>2$. Relationship to Literature: $</ b>$ Does the paper demonstrate an adequate understanding of the relevant literature in the field and cite an appropriate range of literature sources? Is any significant work ignored?: Yes.

The authors thank the Referee for acknowledging the extensive review of related literature.

$<b>3$. Methodology: $</ b>\mid s$ the paper's argument built on an appropriate base of theory, concepts or other ideas? Has the research or equivalent intellectual work on which the paper is based been well designed? Are the methods employed appropriate?: need few improvements as mentioned in the report in order to enhance the readability 
The authors thank the Referee for the useful comments, which have enabled them to enhance the readability of the manuscript. All the proposed changes have been seriously taken into consideration and fully made where appropriate. In other sections, comments and clarifications have been made to keep the aim of the work clear to the reader.

$<b>4$. Results: $</ b>$ Are results presented clearly and analysed appropriately? Do the conclusions adequately tie together the other elements of the paper?: Fairly sufficient

The authors thank the Referee for the comment and wish to drive the Referee's attention to the paragraph titled "Conclusion" which has been revised to bring together the results and discussion, which have also been revised to strengthen the manuscript quality.

$<b>5$. Implications for research, practice and/or society: $</ b>$ Does the paper identify clearly any implications for research, practice and/or society? Does the paper bridge the gap between theory and practice? How can the research be used in practice (economic and commercial impact), in teaching, to influence public policy, in research (contributing to the body of knowledge)? What is the impact upon society (influencing public attitudes, affecting quality of life)? Are these implications consistent with the findings and conclusions of the paper?: Yes.

The authors thank the Referee for the positive comment.

$<b>6$. Quality of Communication: $</ b>$ Does the paper clearly express its case, measured against the technical language of the fields and the expected knowledge of the journal's readership? Has attention been paid to the clarity of expression and readability, such as sentence structure, jargon use, acronyms, etc.: satisfactory

The authors thank the Referee for the comment and wish to confirm that the manuscript has been proofread in full by a British English native speaker, to identify and correct grammar and typo errors. 


\section{References}

Achour, N. and Price, A. D. F. (2010), "Resilience strategies of healthcare facilities: present and future", International Journal of Disaster Resilience in the Built Environment, 1, 3, 264-276.

Albright, R. E. (2002), "How to use roadmapping for global platform products", PDMA visions, 26.

Albright, R. E. and Kappel, T. A. (2003), "Technology roadmapping: roadmapping the corporation", Research technology management, 46, 2, 31.

Ardalan, A., Rajaei, M. H., Masoumi, G., Azin, A., Zonoobi, V. and Sarvar, M. (2012), "2012-2025 Roadmap of IR Iran's Disaster Health Management", PLoS currents, 4.

Benbasat, I., Goldstein, D. K. and Mead, M. (1987), "The Case Research Strategy in Studies of Information Systems", MIS Quarterly, 11, 3, 369-386.

Bloomfield, B. P. and Best, A. (1992), "Management consultants: systems development, power and the translation of problems", Sociological Review, 40.

Bosher, L., Carrillo, P., Dainty, A., Glass, J. and Price, A. (2007), "Realising a resilient and sustainable built environment: towards a strategic agenda for the United Kingdom", Disasters, 31, 3, 236-255.

Bouma, H., van Rest, J., van Buul-Besseling, K., de Jong, J. and Havekes, A. (2015), "Integrated roadmap for the rapid finding and tracking of people at large airports", International Journal of Critical Infrastructure Protection.

Brown, R. and O'Hare, S. (2001), "The use of technology roadmapping as an enabler of knowledge management".

Cepeda Carrión, G., Luis Galán González, J. and Leal, A. (2004), "Identifying key knowledge area in the professional services industry: a case study", Journal of Knowledge Management, 8, 6, 131-150.

Crowley, P. and Lipschutz, L. N. (2013), Mapping out goals, Inside Healthcare.

Curtis, L. and Burns, A. (2015), Unit costs of Health and Social Care 2015, University of Kent.

Denzin, N. K. and Lincoln, Y. S. (2011), The SAGE handbook of qualitative research, SAGE, London.

Department of Energy \& Climate Change (2013), "UK Renewable Energy Roadmap Update 2013", available at: https:/www.gov.uk/government/publications/uk-renewable-energyroadmap-second-update [Accessed 27 November 2015].

Department of Health (2013), "Health Technical Memorandum 07-07: Sustainable health and social care buildings: Planning, design, construction and refurbishment", 62.

Department of Health (2014), "Health Building Note 00-07: Planning for a resilient healthcare estate".

Department of Health (2015), Improving the environment of care for people with dementia. Project Evaluation Report. , Department of Health.

DH (2016), The government's mandate to NHS England for 2016 to 2017, Department of Health,

Eisenhardt, K. M. (1989), "Building Theories from Case Study Research", Academy of Management Review, 14, 4, 532-550.

European Industrial Research Management Association (1997), Technology Roadmapping: Delivering Business Vision, EIRMA,

Francis, R. (2013), Report of the Mid Staffordshire NHS Foundation Trust Public Inquiry, London. 
Froese, T. and Rankin, J. H. (2009), "Strategic roadmaps for construction innovation: assessing the state of research", Journal of Information Technology in Construction (ITcon), 14, Special Issue Next Generation Construction IT: Technology Foresight, Future Studies, Roadmapping, and Scenario Planning, 400-411.

Gabriel, C. and David, M. (2005), "A review of case studies publishing in Management Decision 2003-2004: Guides and criteria for achieving quality in qualitative research", Management Decision, 43, 6, 851-876.

Garcia, M. L. and Bray, O. H. (1997), Fundamentals of Technology Roadmapping, Albuquerque, New Mexico, Sandia National Laboratories.

Gerdsri, N. and Kocaoglu, D. F. (2007), "Applying the Analytic Hierarchy Process (AHP) to build a strategic framework for technology roadmapping", Mathematical and Computer Modelling, 46, 7, 1071-1080.

Groenveld, P. (1997), "Roadmapping integrates business and technology", Research technology management, 40, 5, 48.

Haddad, C. R. and Uriona Maldonado, M. (2017), "A functions approach to improve sectoral technology roadmaps", Technological forecasting and social change, 115, Supplement C, 251-260.

HM Government (2005), Securing the future - delivering UK sustainable development strategy., The Stationery Office,

HM Treasury (2014), "Improving Infrastructure Delivery: Project Initiation Routemap Handbook", available at: https:/www.gov.uk/government/publications/improvinginfrastructure-delivery-project-initiation-routemap [Accessed 27 November 2015].

Kamtsiou, V., Naeve, A., Stergioulas, L. K. and Koskinen, T. (2006), "Roadmapping as a knowledge creation process: The PROLEARN roadmap", Journal of Universal Knowledge Management, 1, 3, 163-173.

Kappel, T. A. (2001), "Perspectives on roadmaps: how organizations talk about the future", Journal of Product Innovation Management, 18, 1, 39-50.

Keogh, B. (2013), Review into the quality of care and treatment provided by 14 hospital trusts in England: overview report, NHS.

Khosrowshahi, F. and Arayici, Y. (2012), "Roadmap for implementation of BIM in the UK construction industry", Engineering, Construction and Architectural Management, 19, 6, 610-635.

Kim, C., Kim, H., Han, S. H., Kim, C., Kim, M. K. and Park, S. H. (2009a), "Developing a technology roadmap for construction R\&amp;D through interdisciplinary research efforts", Automation in Construction, 18, 3, 330-337.

Kim, C., Kim, H., Han, S. H., Kim, C., Kim, M. K. and Park, S. H. (2009b), "Developing a technology roadmap for construction R\&D through interdisciplinary research efforts", Automation in Construction, 18, 3, 330-337.

Klinckenberg, F., Forbes Pirie, M. and McAndrew, L. (2013), Renovation roadmaps for buildings, London Eurima.

Lee, J. H., Phaal, R. and Lee, S.-H. (2013), "An integrated service-device-technology roadmap for smart city development", Technological forecasting and social change, 80, 2, 286-306.

Lee, S. and Park, Y. (2005), "Customization of technology roadmaps according to roadmapping purposes: Overall process and detailed modules", Technological forecasting and social change, 72, 5, 567-583.

Leveson, N., Dulac, N., Zipkin, D., Cutcher-Gershenfeld, J., Carroll, J. and Barrett, B. (2006), "Engineering resilience into safety-critical systems", Resilience EngineeringConcepts and Precepts. Ashgate Aldershot, 95-123. 
Lord Carter of Coles (2015), Review of Operational Productivity in NHS providers. Interim Report., Department of Health.

Lord Carter of Coles (2016), Operational productivity and performance in English NHS acute hospitals: Unwarranted variations, Department of Health.

Manyena, S. B. (2006), "The concept of resilience revisited", Disasters, 30, 4, 434-450.

Mills, G. R. W., Deka, L., Price, A. D. F., Rich-Mahadkar, S., Pantzartzis, E. and Sellars, P. (2015), "Critical infrastructure risk in NHS England: predicting the impact of building portfolio age", International Journal of Strategic Property Management, 19, 2, 159-172.

National Information Board (2015), "Delivering the Five Year Forward View. Personalised Health and Care 2020", available at:

https://www.gov.uk/government/publications/implementing-personalised-health-andcare-2020 [Accessed 27 November 2015].

NHS (2014), Five Year Forward View, NHS England.

NHS (2015), Five Year Forward View - Time to deliver, NHS England.

NHS (2019), The NHS Long Term Plan, NHS England.

NIB and Department of Health (2014), "Personalised health and care 2020", available at: https://www.gov.uk/government/publications/personalised-health-and-care-2020 [Accessed 27 November 2015].

Nirupama, N., Popper, T. and Quirke, A. (2015), "Role of social resilience in mitigating disasters", International Journal of Disaster Resilience in the Built Environment, 6, 3, 363-377.

Pantzartzis, E., Deka, L., Tann, C., Mills, G. R., Mahadkar, S. and Price, A. D. F. (2016a), "Sustainable management of NHS assets backlog maintenance", Built Environment Project and Asset Management, accepted.

Pantzartzis, E., Price, A. D. F. and Pascale, F. (2016b), "A built environment response to the rising costs of dementia", Journal of Financial Management of Property and Construction, 21, 2.

Petrick, I. J. and Echols, A. E. (2004), "Technology roadmapping in review: A tool for making sustainable new product development decisions", Technological forecasting and social change, 71, 1, 81-100.

Phaal, R., Farrukh, C. and Probert, D. (2001), "Technology Roadmapping: linking technology resources to business objectives", Centre for Technology Management, University of Cambridge, 1-18.

Phaal, R., Farrukh, C. J. and Probert, D. R. (2004), "Technology roadmapping - a planning framework for evolution and revolution", Technological forecasting and social change, 71, 1, 5-26.

Probert, D. and Radnor, M. (2003), "Technology roadmapping: frontier experiences from industry-academia consortia", Research technology management, 46, 2, 27.

Rinne, M. (2004), "Technology roadmaps: Infrastructure for innovation", Technological forecasting and social change, 71, 1-2, 67-80.

Robinson, H. S., Anumba, C. J., Carrillo, P. M. and Al-Ghassani, A. M. (2006), "STEPS: a knowledge management maturity roadmap for corporate sustainability", Business Process Management Journal, 12, 6, 793-808.

Robinson, J. and Cole, R. J. (2015), "Theoretical underpinnings of regenerative sustainability", Building Research \& Information, 43, 2, 133-143.

Rogers, P. (2015), "Researching resilience: An agenda for change", Resilience, 3, 1, 55-71.

Singer, B. C. (2010), High Performance Healthcare Buildings: A Roadmap to Improved Energy Efficiency.

Straube, B. (2005), "The CMS Quality Roadmap: quality plus efficiency", Health Affairs, 24, W5. 
Strauss, J., Radnor, M. and Peterson, J., "Plotting and navigating a non-linear roadmap: knowledge-based roadmapping for emerging and dynamic environments", Proceedings of the East Asian Conference on Knowledge Creation Management,6-7.

Sustainable Development Unit (2013), Route map for sustainable health, Cambridge, Sustainable Development Unit

UNISDR (2005), Hyogo Framework for Action 2005-2015: Building the Resilience of Nations and Communities to Disasters, United Nations International Strategy for Disaster Reduction.

UNISDR (2015), Sendai Framework for Disaster Risk Reduction 2015-2030, United Nations International Strategy for Disaster Reduction.

United Nations (2015a), The Millennium Development Goals Report 2015, In: Way, C. (ed.), New York, United Nations.

United Nations (2015b), Transforming our world: the 2030 Agenda for Sustainable Development, United Nations,

Velilla, N. M., Bouzon, C. A., Contin, K. C., Beroiz, B. I., Herrero, Á. C. and Renedo, J. A. (2012), "Different Functional Outcomes in Patients with Delirium and Subsyndromal Delirium One Month after Hospital Discharge", Dementia and Geriatric Cognitive Disorders, 34, 5-6, 332-336.

Vishnevskiy, K., Karasev, O. and Meissner, D. (2015), "Integrated roadmaps and corporate foresight as tools of innovation management: The case of Russian companies", Technological forecasting and social change, 90, Part B, 433-443.

WCED (1987), Our Common Future, Oxford, United Nations.

Wells, R., Phaal, R., Farrukh, C. and Probert, D. (2004), "Technology roadmapping for a service organization", Research technology management, 47, 2, 46.

World Economic Forum (2015), Global Risk 2015, 10th ed., Geneva, World Economic Forum.

Zhong, S., Clark, M., Hou, X. Y., Zang, Y. L. and Fitzgerald, G. (2014), "Proposing and developing a definition and conceptual framework for health care resilience to cope with disasters", Emergencias, 26, 69-77. 
Table 1. Roadmap definitions from literature

\begin{tabular}{|c|c|}
\hline Author (year) & Definition \\
\hline $\begin{array}{l}\text { Garcia and Bray } \\
\text { (1997) }\end{array}$ & A document generated by the technology road mapping process. \\
\hline Groenveld (1997) & $\begin{array}{l}\text { A strategic decision process framework that: supports enterprise innovation } \\
\text { activities; and contributes to the integration of business and technology. }\end{array}$ \\
\hline $\begin{array}{l}\text { Strauss et al. } \\
(1998)\end{array}$ & $\begin{array}{l}\text { An operational toolset based on strategic plan requirements for selecting which } \\
\text { technologies/products to pursue and in what timeframes. }\end{array}$ \\
\hline $\begin{array}{l}\text { Brown and O'Hare } \\
(2001)\end{array}$ & $\begin{array}{l}\text { A visual aid which crystallises the links between research programmes, } \\
\text { development programmes, capability targets and requirements. }\end{array}$ \\
\hline Kappel (2001) & $\begin{array}{l}\text { A strategic document to: establish market, product and technology priorities; } \\
\text { extend them using forecasts to set targets; and links them through R\&D } \\
\text { investments. }\end{array}$ \\
\hline Albright (2002) & $\begin{array}{l}\text { A planning tool to help the team communicate their objectives and plans (i.e. } \\
\text { discipline to ensure there are no gaps in the plan) to the larger development } \\
\text { team, to other corporate functions. }\end{array}$ \\
\hline $\begin{array}{l}\text { Probert and } \\
\text { Radnor (2003) }\end{array}$ & $\begin{array}{l}\text { The view of a group of stakeholders as to how to get where they want to go to } \\
\text { achieve their desired objective. }\end{array}$ \\
\hline Phaal et al. (2004) & $\begin{array}{l}\text { An approach to support the development, communication and implementation } \\
\text { of technology and business strategy. }\end{array}$ \\
\hline $\begin{array}{l}\text { Petrick and Echols } \\
\text { (2004) }\end{array}$ & $\begin{array}{l}\text { A tool to enable managers making sustainable new product development } \\
\text { decisions. }\end{array}$ \\
\hline Rinne (2004) & $\begin{array}{l}\text { A tool for managing the future of technologies and the products that implement } \\
\text { them. }\end{array}$ \\
\hline Wells et al. (2004) & $\begin{array}{l}\text { A communication/knowledge management tool supporting strategic decision- } \\
\text { making. }\end{array}$ \\
\hline $\begin{array}{l}\text { Lee and Park } \\
(2005)\end{array}$ & $\begin{array}{l}\text { A method for supporting the strategic management of technology (i.e. planning, } \\
\text { forecasting, and administration). }\end{array}$ \\
\hline $\begin{array}{l}\text { Kamtsiou et al. } \\
(2006)\end{array}$ & $\begin{array}{l}\text { A tool for collaborative strategic planning that enables us to make strategies and } \\
\text { take actions towards the desired future, with special emphasis on anticipating } \\
\text { changes in technologies and new business opportunities. }\end{array}$ \\
\hline Gerdsri and & A collective approach to developing a strategy in which the integration of \\
\hline Kocaoglu (2007) & $\begin{array}{l}\text { science/ technological considerations represents a valuable input into product } \\
\text { and business planning. }\end{array}$ \\
\hline $\begin{array}{l}\text { Froese and Rankin } \\
(2009)\end{array}$ & $\begin{array}{l}\text { A framework based on three classification facets (i.e. application area, } \\
\text { technology, and innovation lifecycle phase) defines a three-dimensional space } \\
\text { (i.e. the construction innovation space). }\end{array}$ \\
\hline $\begin{array}{l}\text { Ardalan et al. } \\
(2012)\end{array}$ & $\begin{array}{l}\text { A systematic process of using administrative decisions, organisation, } \\
\text { operational skills and capacities to meet the challenge of planning for, } \\
\text { responding to, recovering from and mitigating health consequences of disasters. }\end{array}$ \\
\hline Crowley and & A decision-making tool that provides information for goal definition, option \\
\hline Lipschutz (2013) & $\begin{array}{l}\text { analysis, consensus-based, informed decision making and ultimately, rapid } \\
\text { implementation of priority projects. }\end{array}$ \\
\hline $\begin{array}{l}\text { Klinckenberg et } \\
\text { al. (2013) }\end{array}$ & $\begin{array}{l}\text { A high-level policy tool that focuses on stakeholder coordination, effective } \\
\text { communications and shared long-term vision. }\end{array}$ \\
\hline Lee et al. (2013) & $\begin{array}{l}\text { A rational methodology for seeking agreement when selecting technologies } \\
\text { supporting organisational goals and a framework that may be used for } \\
\text { establishing and adjusting technology development time-lines. }\end{array}$ \\
\hline SDU (2013) & A framework for action to develop a sustainable health system. \\
\hline
\end{tabular}


Table 2. Roadmap specifications and processes in technology sector from literature

\begin{tabular}{|c|c|c|c|c|}
\hline Author (year) & Type & Aim & Specifications & Processes \\
\hline $\begin{array}{l}\text { Lee et al. } \\
(2013)\end{array}$ & Product & $\begin{array}{l}\text { To seek agreement when } \\
\text { selecting technologies } \\
\text { supporting } \\
\text { organisational goals, and } \\
\text { to establish and adjust } \\
\text { technology development } \\
\text { timelines. }\end{array}$ & $\begin{array}{l}\text { Time, vision, goals, } \\
\text { scope, CSFs, team, } \\
\text { technology, } \\
\text { performance, customer } \\
\text { demands, customer } \\
\text { needs, sustainability, } \\
\text { value (use), quality } \\
\text { standards, availability, } \\
\text { applicability, and } \\
\text { security. }\end{array}$ & $\begin{array}{l}\text { Planning; demand } \\
\text { identification; service } \\
\text { identification; device } \\
\text { identification; } \\
\text { technology } \\
\text { identification; } \\
\text { development; } \\
\text { adjustment; and follow- } \\
\text { up. }\end{array}$ \\
\hline $\begin{array}{l}\text { Kamtsiou et } \\
\text { al. (2006) }\end{array}$ & Process & $\begin{array}{l}\text { To map out the desired } \\
\text { future for technology- } \\
\text { enhanced professional } \\
\text { learning in the form of } \\
\text { prevalent visions in the } \\
\text { community at large. }\end{array}$ & $\begin{array}{l}\text { Time, vision, team, and } \\
\text { capabilities. }\end{array}$ & $\begin{array}{l}\text { Foresight phase (i.e. } \\
\text { current state and vision); } \\
\text { and planning phase (i.e. } \\
\text { gap analysis, } \\
\text { capabilities, and action } \\
\text { plan). }\end{array}$ \\
\hline $\begin{array}{l}\text { Lee and Park } \\
(2005)\end{array}$ & Process & $\begin{array}{l}\text { To support the strategic } \\
\text { management (i.e. } \\
\text { forecasting, planning, } \\
\text { and administration) of } \\
\text { technology. }\end{array}$ & $\begin{array}{l}\text { Time, business needs, } \\
\text { targets, technology, risk } \\
\text { plan, and environmental } \\
\text { conditions. }\end{array}$ & $\begin{array}{l}\text { Classification (i.e. } \\
\text { purpose and type); } \\
\text { standardisation (i.e. } \\
\text { product and } \\
\text { technology); and } \\
\text { modularization (i.e. } \\
\text { planning, forecasting } \\
\text { and administration). }\end{array}$ \\
\hline $\begin{array}{l}\text { Petrick and } \\
\text { Echols (2004) }\end{array}$ & Process & $\begin{array}{l}\text { To organise data into } \\
\text { meaningful categories } \\
\text { that can be manipulated } \\
\text { both temporarily and } \\
\text { across organisational } \\
\text { functions. }\end{array}$ & $\begin{array}{l}\text { Time, market needs, } \\
\text { resources, risk plan, } \\
\text { capabilities, ROI, trust, } \\
\text { competency, } \\
\text { sustainability, } \\
\text { innovation, } \\
\text { performance, and } \\
\text { information transfer. }\end{array}$ & NP \\
\hline $\begin{array}{l}\text { Phaal et al. } \\
\text { (2004) }\end{array}$ & Process & $\begin{array}{l}\text { To support } \\
\text { development, } \\
\text { communication and } \\
\text { implementation of } \\
\text { technology and business } \\
\text { strategy. }\end{array}$ & $\begin{array}{l}\text { Time, socio-technical } \\
\text { change, value, goals, } \\
\text { targets, technologies, } \\
\text { market, resources, } \\
\text { capabilities, ownership, } \\
\text { and communication. }\end{array}$ & $\begin{array}{l}\text { Planning (i.e. market, } \\
\text { product, and } \\
\text { technology); and } \\
\text { customising (i.e. setting } \\
\text { up, managing, and } \\
\text { following on). }\end{array}$ \\
\hline Rinne (2004) & Process & $\begin{array}{l}\text { To formulate future } \\
\text { strategy, to solicit and } \\
\text { justify funding, to } \\
\text { forecast technology and } \\
\text { product changes. }\end{array}$ & $\begin{array}{l}\text { Time, profitability, risk } \\
\text { plan, cost, organisation } \\
\text { capability, feedback, } \\
\text { and audience. }\end{array}$ & $\begin{array}{l}\text { Representation; } \\
\text { communication; } \\
\text { planning; and } \\
\text { coordination. }\end{array}$ \\
\hline $\begin{array}{l}\text { Albright and } \\
\text { Kappel (2003) }\end{array}$ & Product & $\begin{array}{l}\text { To define the plan for } \\
\text { the evolution of a } \\
\text { product, linking } \\
\text { business strategy to the } \\
\text { evolution of the product } \\
\text { features and costs to the } \\
\text { technologies needed to } \\
\text { achieve the strategic } \\
\text { objective. }\end{array}$ & $\begin{array}{l}\text { Time, needs, gaps, } \\
\text { policy, language, } \\
\text { market, product, } \\
\text { technologies, risk plan, } \\
\text { and cost. }\end{array}$ & $\begin{array}{l}\text { Strategy; and action } \\
\text { plan. }\end{array}$ \\
\hline $\begin{array}{l}\text { Albright } \\
(2002)\end{array}$ & Product & $\begin{array}{l}\text { To lay out the evolution } \\
\text { and timing of platform }\end{array}$ & $\begin{array}{l}\text { Time, market needs, } \\
\text { priorities, goals, }\end{array}$ & $\begin{array}{l}\text { Strategy; and action } \\
\text { plan. }\end{array}$ \\
\hline
\end{tabular}


products to serve multiple, changing market segments.

Strauss et al. Product To detail (1998) implementation of plans, converting explicit inputs and tacit knowledge into more usable and understandable explicit knowledge.

Garcia and Process To provide information Bray (1997) to make better technology investment decisions by identifying critical technologies and technology gaps and identifying ways to leverage $R \& D$ investments.

Product

\section{To explore opportunities} and risks of markets, products and technologies over time. customer needs, capabilities, team, performance, technology, risk plan, and cost.

Time, market needs, Define content; develop product attributes, goals, the product technology requirements, priorities, RM; and follow-up and evolution plan. activities.

Time, perceived needs, scope, stakeholders, targets, specifications, technologies, and requirements.

Preliminary activity (i.e. scope and specifications); development (i.e. targets, requirements and technologies); and follow-up (i.e. implementation plan).

Time, market, product, NP and technology. 
Table 3. Roadmap specifications and processes in construction sector from literature

\begin{tabular}{|c|c|c|c|c|}
\hline Author (year) & Type & Aim & Specifications & Processes \\
\hline $\begin{array}{l}\text { Bouma et al. } \\
(2015)\end{array}$ & Process & $\begin{array}{l}\text { To match short-term and } \\
\text { long-term goals with } \\
\text { specific technological } \\
\text { solutions. }\end{array}$ & $\begin{array}{l}\text { Time, scale, cost, } \\
\text { security, business } \\
\text { continuity, technologies, } \\
\text { performance, resources, } \\
\text { training, trust, culture, } \\
\text { communications, role } \\
\text { definitions, legal } \\
\text { aspects, and risk plans. }\end{array}$ & $\begin{array}{l}\text { Starting point; desired } \\
\text { end condition; external } \\
\text { factors; and scope of } \\
\text { functionality. }\end{array}$ \\
\hline $\begin{array}{l}\text { Klinckenberg } \\
\text { et al. }(2013)\end{array}$ & Product & $\begin{array}{l}\text { To identify precise } \\
\text { objectives and helps } \\
\text { focus resources on the } \\
\text { critical technologies that } \\
\text { are needed to meet those } \\
\text { objectives. }\end{array}$ & $\begin{array}{l}\text { Time, policy, EB-data, } \\
\text { goals, targets, market, } \\
\text { performance, } \\
\text { stakeholders, } \\
\text { requirements, financial } \\
\text { support, consumers' } \\
\text { education, state-of-the- } \\
\text { art, legislations, cost, } \\
\text { consumer education, and } \\
\text { organisation support. }\end{array}$ & $\begin{array}{l}\text { Initiating the process; } \\
\text { roadmap development; } \\
\text { progress and evaluation. }\end{array}$ \\
\hline $\begin{array}{l}\text { Khosrowshahi } \\
\text { and Arayici } \\
(2012)\end{array}$ & Process & $\begin{array}{l}\text { To lay the foundation } \\
\text { for the UK construction } \\
\text { industry to prepare } \\
\text { moving up top maturity } \\
\text { ladder. }\end{array}$ & NP & NP \\
\hline $\begin{array}{l}\text { Froese and } \\
\text { Rankin (2009) }\end{array}$ & Process & $\begin{array}{l}\text { To support } \\
\text { knowledgeable } \\
\text { decisions (i.e. mental } \\
\text { checklist of topics and } \\
\text { perspectives) on } \\
\text { adoption and } \\
\text { implementation of } \\
\text { construction } \\
\text { innovations. }\end{array}$ & $\begin{array}{l}\text { Time, performance, } \\
\text { application areas, } \\
\text { technologies, } \\
\text { innovation, gaps (supply } \\
\text { - demand), scale, } \\
\text { objectives, and ICT. }\end{array}$ & $\begin{array}{l}\text { Adopt new } \\
\text { technologies; implement } \\
\text { knowledge; and meet } \\
\text { the constraints. }\end{array}$ \\
\hline $\begin{array}{l}\text { Kim et al. } \\
(2009)\end{array}$ & Process & $\begin{array}{l}\text { To significantly improve } \\
\text { business performance, } \\
\text { by providing chances to } \\
\text { learn new ways of } \\
\text { reasoning and problem- } \\
\text { solving. }\end{array}$ & $\begin{array}{l}\text { Market needs, goals, } \\
\text { performance, SROI, } \\
\text { benchmarking, } \\
\text { technology, and socio- } \\
\text { economic value. }\end{array}$ & $\begin{array}{l}\text { Environmental } \\
\text { scanning; and roadmap } \\
\text { development. }\end{array}$ \\
\hline $\begin{array}{l}\text { Robinson et } \\
\text { al. (2006) }\end{array}$ & Process & $\begin{array}{l}\text { To facilitate the } \\
\text { implementation of } \\
\text { knowledge management } \\
\text { strategy in construction } \\
\text { organisations. }\end{array}$ & $\begin{array}{l}\text { Time, goals, business } \\
\text { objectives, leadership, } \\
\text { resources, IT, tools, } \\
\text { implementation plan, } \\
\text { performance, customers, } \\
\text { impact on society (e.g. } \\
\text { pollution, safety, } \\
\text { accidents, and resources } \\
\text { preservation). }\end{array}$ & $\begin{array}{l}\text { Start-up; take-off; } \\
\text { expand; progress; and } \\
\text { sustain. }\end{array}$ \\
\hline
\end{tabular}


Table 4. Emerging sub-layers for resilient and sustainable performance

\begin{tabular}{|c|c|c|c|}
\hline Layer & Research stream 1 & Research stream 2 & Research stream 3 \\
\hline \multirow{8}{*}{ Organisation } & Accountability & & Accountability \\
\hline & Assurance & & \\
\hline & & Awareness & \\
\hline & & Communication & Communication \\
\hline & Culture & Culture & \\
\hline & & Engagement & \\
\hline & Knowledge & & Knowledge \\
\hline & & Training & \\
\hline \multirow{8}{*}{ Infrastructure } & Age of buildings & & \\
\hline & Building components & Building components & \\
\hline & & Building spaces & \\
\hline & Investment & Investment & \\
\hline & Maintenance & & \\
\hline & 2 & Space capacity & Space capacity \\
\hline & 2 & Space location & Space location \\
\hline & 8 & & Space utilisation \\
\hline \multirow{8}{*}{ Process } & Data gathering & & Data gathering \\
\hline & Data management & Data management & Data management \\
\hline & & & Energy \\
\hline & 8 & Guidance & \\
\hline & 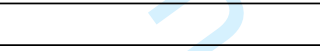 & Integrated-care delivery & \\
\hline & Performance metrics & Performance metrics & Performance metrics \\
\hline & Service delivery & & Service delivery \\
\hline & 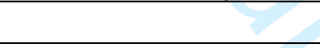 & Technology & \\
\hline
\end{tabular}




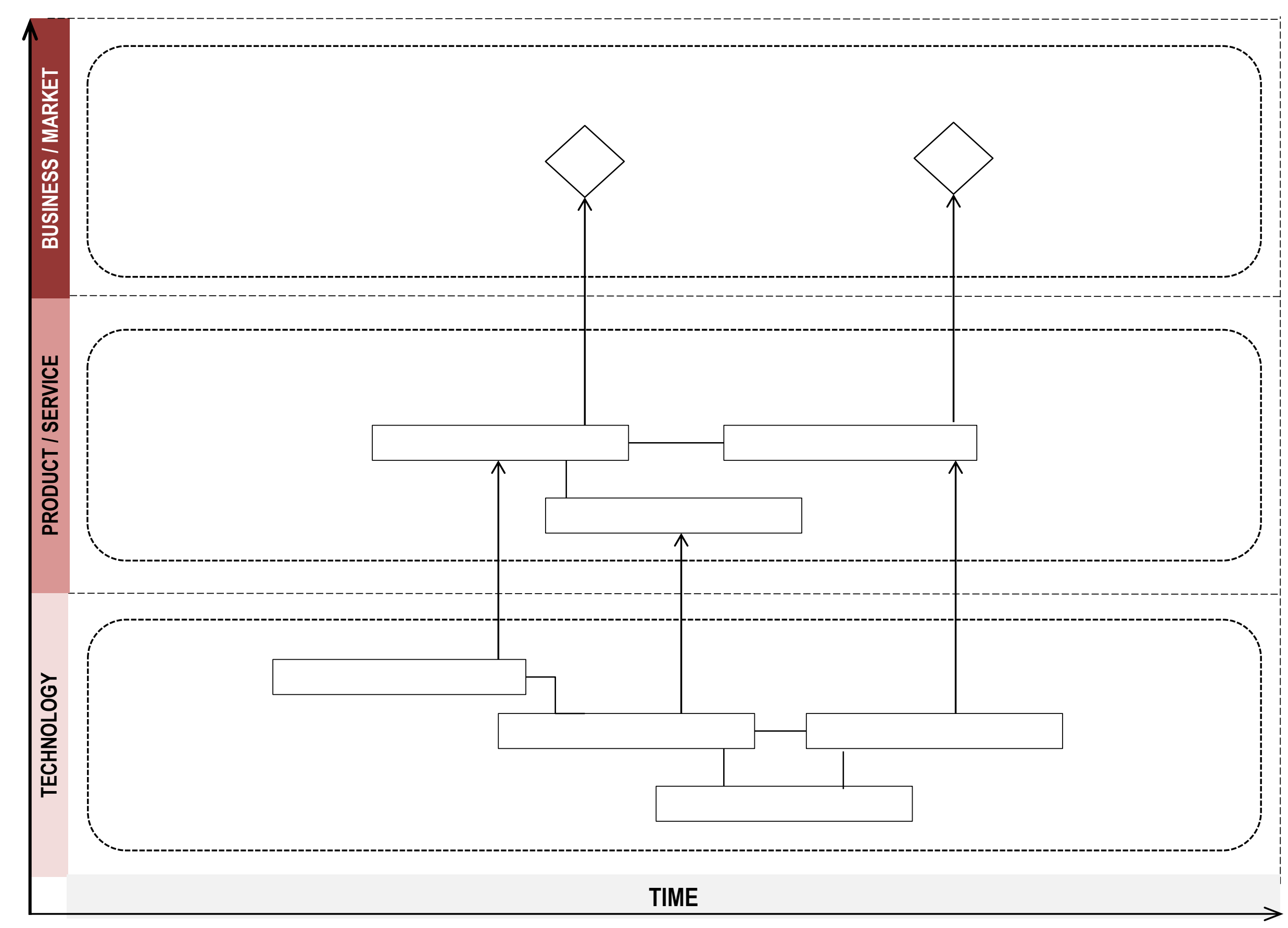

Figure 1. Layered technology roadmap structure adapted EIRMA, 1997 


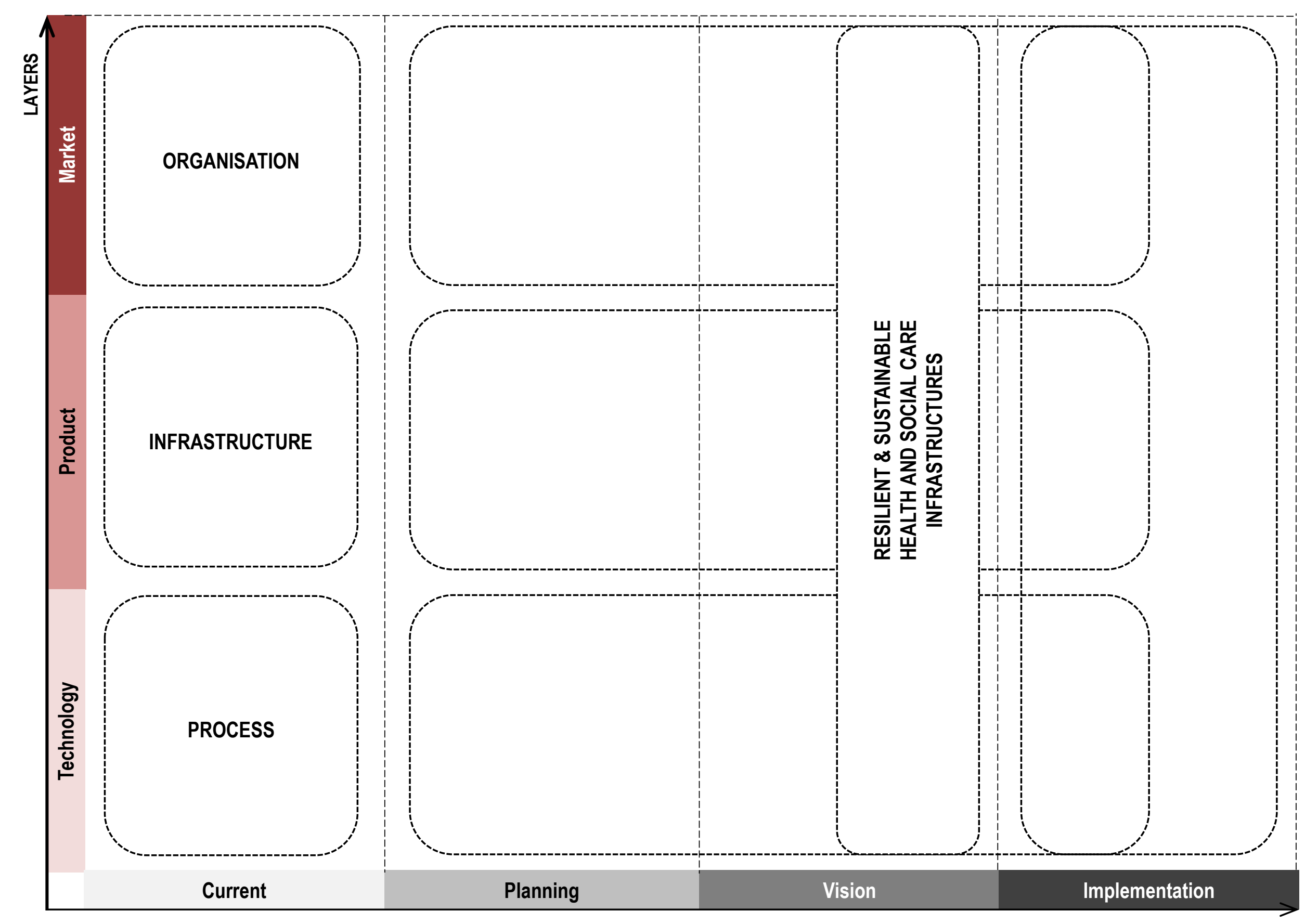

TIME

Figure 2. Roadmap for resilience and sustainability of health and social care infrastructures: layers and processes 